\title{
Hydrodynamic interactions between two ships travelling or stationary in shallow waters
}

\author{
${ }^{*}$ Zhi-Ming Yuan, Atilla Incecik, Saishuai Dai, Day Alexander \\ Department of Naval Architecture, Ocean and Marine Engineering \\ University of Strathclyde, Glasgow, UK
}

\begin{abstract}
In this paper, a boundary element program MHydro, which is based on 3-D Rankine source method, was developed to investigate the ship-to-ship interaction problem. The method developed considers both stationary and forward speed cases. A new radiation condition, which takes Doppler shift into account, is imposed on the control surface. For the stationary case, the validations were carried out both in head sea and beam sea conditions. The experimental measurements, as well as the published numerical results, were used for the comparison. For the ship-to-ship with forward speed case, we validated our method through the experimental tests. Good agreement was achieved except the roll motion. The hydrodynamic coefficients and wave excitation forces were investigated and a very large sway force was predicted when the transverse distance between two ships equalled to the wave length. The wave elevations in the gap were also calculated. Discussions are highlighted on the shallow water effects.
\end{abstract}

Keywords: Hydrodynamic interaction; Rankine source method; Radiation condition; Wave pattern; Forward speed; Shallow water.

\section{Introduction}

Lightering operations with forward speed are important for the transfer of fuel in naval operations. Nowadays, lighting operations without forward speed is important for the LNG offloading from LNG FPSOs or FSRUs (Floating Storage and Regassification Units). The loads in the mooring lines between the two vessels, the loads in the floating fenders and the relative motions at the manifold location are the most critical issues during this operation. These are determined by the wave, wind and current loads on the two vessels in close proximity, as well as by the strong hydrodynamic interaction between the vessels. Even in head seas, the two vessels could be subjected to a very large separating force as the waves run between the two hulls. The resulting motions and mooring loads determine the operability of the operation in certain environmental conditions.

Early studies on the hydrodynamic interaction problem focused on 2-D strip theory. Ohkusu (1974) used the multipoles method and theory to calculate the response of parallel, slender, ship like bodies in beam waves.

\footnotetext{
* Corresponding author at: Dep. of Naval Architecture, Ocean \& Marine Engineering, University of Strathclyde. Henry Dyer Building, G4 0LZ, Glasgow, UK.

Tel: + 44 (0)141548 3308. Fax: +44 (0)141 5522879 .

E-mail address: zhiming.yuan@strath.ac.uk
} 
His results clearly illustrated the effect of position of a smaller body on the weather and lee side against a large body. Kodan (1984) extended Ohkusu's theory (Ohkusu, 1974) to hydrodynamic interaction between two parallel structures in oblique waves by strip method. Fang and Kim (1986) analysed the hydrodynamically coupled motions of two longitudinally parallel barges advancing in oblique waves by strip method. His analysis showed that the coupled motions of two advancing ships depend on the speed, wave heading and distance. The 2-D method was a simple and effective tool in predicting the hydrodynamic interaction between two adjacent ships. Ronæss (2002) applied a unified slender body theory to investigate the ship-to-ship with forward speed problem. Her results showed good agreement with her model tests at the Marine Technology Centre in Trondheim, Norway. However, the limitations of applying 2-D methods in the ship-to-ship interaction problem in waves have been confirmed by Fang and Kim (1986). The two ships were assumed to be in each other's near-field. The 2-D method overestimated the interaction effects due to the wave energy trapping between the two hulls in the frequency range which is important for ship motions, which also leads to the overestimation of the mean second-order wave loads on each ship. Besides, the strip theory can only predict the motion responses of conventional monohull ship in waves at low to moderate Froude numbers. However at high Froude numbers, three-dimensional (3-D) effects become dominant and strip theory fails to predict the hydrodynamic performance of vessels travelling with high forward speed. Under these circumstances, an advanced computational technique which accounts for the 3D flow interactions is necessary for motion and loading prediction.

Chen and Fang (2001) extended Fang's method (Fang and Kim, 1986) to 3-D. They used a 3-D Green function method to investigate the hydrodynamic problems between two moving ships in waves. It was found that the hydrodynamic interactions calculated by a 3-D method were more reasonable in the resonance region, where the responses were overestimated by 2-D method. However, their method was only validated by model tests with zero speed. More rigorous validation should be made by further experiments. Kim and Ha (2002) used 3-D pulsating source distribution techniques to calculate twelve coupled linear motion responses and relative motions of the barge and the ship in oblique waves. Their computational results gave a good correlation with the experimental results and also with other numerical results. Taggart et al. (2003) and Li (2007) developed a frequency domain code based on 3-D Green function method. They validated their numerical predictions by model tests conducted at the Institute for Marine Dynamics (IMD) in St. John's, Newfoundland. It was showed that the presence of a larger ship could significantly influence the motions of a smaller ship in close proximity. But the numerical prediction of roll motion was not accurate. Kashiwagi et al. (2005) investigated the wave drift forces and moments on two ships stationary in waves by using 3D HOBEM. They compared their method to the model test results and obtained a good agreement. Xu and Faltinsen (2011) used a 3-D Rankine source method to solve the linear initial-boundary value problem of two ships advancing in waves. The time domain analysis was validated through the frequency solution via Fourier transform, and also the model test results. Recently, within the frame work of Green function, Xu and Dong (2013) developed a 3-D translating-pulsating (3DTP) source method to calculate wave loads and free motions of two 
ships advancing in waves. Model tests were carried out to measure the wave loads and the heave, roll and pitch motions for a pair of side-by-side arranged ship models advancing with an identical speed in head regular waves. Both the experiment and the numerical prediction showed that hydrodynamic interaction effects on wave loads and motions were significant. They also pointed out that the prediction accuracy of the 3DTP method was much better than that of 3DP, especially for peak values of the motion responses.

Most work on ship-to-ship interaction problem assumes that the water is infinitely deep. In deep water, the major stimulus for systematic study of the phenomenon arose from the needs of the warship replenishing while underway at sea. It has already been pointed out that merchant ships are most likely to be in close quarters situation in shallow water where interaction effects may be larger. Meanwhile, the increasing demands for LNG and the associated safety requirements has resulted in a large number of offshore LNG terminal developments and most of these are located near-shore, in relatively shallow water. In addition to shallow water effects on the waves, the clearance to the bottom might become an issue when the water depth to draft ratio becomes small. Ship motions are directly affected in two ways by the restricted water depth: (1) the incident waves are changed and as a result, the wave exciting forces exerted on ship differ from those in deep water; (2) the hydrodynamic coefficients of the ship (i.e. radiation forces) are changed by the nearness of the sea bottom. We also find that most of the publications on two ships with forward speed problem are based on Green function that satisfies the Kelvin free surface conditions, as well as the radiation condition. It is an effective method for the zero forward problems, but if the vessel is travelling with forward speed, this method still has some limitations. Firstly, it could not account for the near-field flow condition. Although some researchers (Lee and Sclavounos, 1989; Nossen et al., 1991) extended it to include the near-field free surface condition, the so-called irregular frequency still cannot be avoided. This will bring singularity to the coefficient matrix equation. Secondly, it is impossible for the Green function to account for the interaction between the steady and unsteady flow.

In the present study, the Rankine source approach proposed by Hess and Smith (Hess and Smith, 1964) will be applied, which uses a very simple Green function in the boundary integral formulation. This method requires the sources distributed not only on the body surface, but also on the free surface, control surface and sea bottom. Therefore, a flexible choice of free-surface condition and sea bottom condition can be realized in these methods. The forward speed and shallow water effects can be directly taken into the consideration in the boundary value problem. Besides, the near field wave elevations can be directly obtained by boundary integration on the free surface. In order to complete the boundary value problem, a radiation condition should be imposed on the control surface. A commonly used treatment was proposed by Nakos (1990). The free surface was truncated at some upstream points, and two boundary conditions were imposed at these points to ensure the consistency of the upstream truncation of the free surface. Another method to deal with the radiation condition is to move the source points on the free surface at some distance downstream (Jensen et al., 1986). The results from these two methods show very good agreement with published experimental data when the parameter $\tau\left(\tau=\omega_{e} u / g, \omega_{e}\right.$ is the encounter frequency, $u$ is the forward speed, and $g$ is the gravitational 
acceleration) is greater than 0.25 , since they are both based on the assumption that there is no scattered wave travelling ahead of the vessel. However, when the forward speed of the vessel is very low, the parameter $\tau$ will be smaller than 0.25 and the scattered waves could travel ahead of the vessel. These traditional radiation conditions could no longer be valid. For ship-to-ship problem, the forward speed is usually limited to a low level for the safe operations. Therefore, a new extensive radiation condition is required to deal with the very low forward speed problem. Here a new modified Sommerfeld radiation condition (Das and Cheung, 2012; Yuan et al., 2014a; Yuan et al., 2014b) was used, which was applicable to a wide range of forward speeds, including the very low forward speed problem where the parameter is smaller than 0.25. Yuan et al. (2014a) validated this radiation condition through model experiments and a very satisfactory agreement was obtained. They also computed the wave elevation on the free surface, and a reasonable wave pattern was obtained at $\tau<$ 0.25 by using their new radiation condition. In this paper, we will apply this new radiation condition to the ship-to-ship problem. A 3-D panel code MHydro, which is based on Rankine source method, will be developed to investigate the hydrodynamic interaction between two vessels with forward speed arranged side by side in shallow water. The motion responses of both ships will be calculated and compared to these obtained from commercial software and experimental results. Discussions are highlighted on the shallow water effects.

\section{Mathematical formulations of the potentials}

\subsection{Coordinate systems}

The corresponding right-handed coordinate systems are shown in Fig. 1. The body coordinate systems $o_{a^{-}}$ $x_{a} y_{a} z_{a}$ and $o_{b}-x_{b} y_{b} z_{b}$ are fixed on Ship_a and Ship_b respectively with their origins on the mean free surface at midships. $o_{a}-z_{a}$ and $o_{b}-z_{b}$ are both positive upwards. $O-X Y Z$ is the earth-fixed coordinate system with its origin located on the calm free surface and $O Z$ axis positive upwards. $d t$ and $d l$ denote the transverse and longitudinal distance between the two ships respectively. The incident wave direction is defined as the angle between the wave propagation direction and $X$-axis. $\beta=180^{\circ}$ corresponds to head sea; $\beta=90^{\circ}$ corresponds to beam sea. $d t$ denotes the transverse distance between two ships while $d l$ is the longitudinal distance. $u_{0}$ is the forward speed.

In the computation, the motions and forces of Ship_a and Ship_b are concerted to the local coordinate system in which the origin is at the centre of gravity of each ship.

\subsection{Diffraction wave potential}

The presence of a ship in waves will influence the incident wave field and generate a diffracted wave field. The diffraction problem will be solved for the presence of both ships. Based on the assumption that the surrounding fluid is inviscid and incompressible, and that the motion is irrotational, the total velocity potential exists which satisfies the Laplace equation in the whole fluid domain. For linearization, the diffraction potential can be written as: 


$$
\begin{aligned}
\Psi_{D}(\vec{x}, t) & =\operatorname{Re}\left[\eta_{7} \varphi_{7}(x, y, z) e^{-i \omega_{e} t}\right] \\
\omega_{e} & =\omega_{0}-u_{0} k \cos \beta
\end{aligned}
$$

Linear wave theory provides the potential for incident waves as

$$
\begin{gathered}
\varphi_{0}=-\frac{i g \eta_{0}}{\omega_{0}} \frac{\cosh k(z+d)}{\cosh k d} e^{i[k(x \cos \beta+y \sin \beta)]} \\
k \cdot \tanh k d=\omega_{0}^{2} / g
\end{gathered}
$$

where $\varphi_{7}$ is the spatial diffraction potential; $\eta_{7}=\eta_{0}$ is the incident wave amplitude; $\vec{x}=(x, y, z)$ is the spatial vector in the fluid domain; $\omega_{0}$ is the incident wave frequency; $\omega_{e}$ is the encounter frequency; $d$ is the water depth; $\beta$ is the angle of wave heading; $k$ is the wave number. The diffraction potential can be solved by the following boundary value problem:

$$
\nabla^{2} \varphi_{7}=0 \quad \text { in the fluid domain }
$$

$$
g \frac{\partial \varphi_{7}}{\partial z}-\omega_{e}^{2} \varphi_{7}+2 i \omega_{e} u_{0} \frac{\partial \varphi_{7}}{\partial x}+u_{0}^{2} \frac{\partial^{2} \varphi_{7}}{\partial x^{2}}=0 \quad \text { on the undisturbed free surface } S_{f}
$$

$$
\begin{gathered}
\frac{\partial \varphi_{7}}{\partial n}=-\left.\frac{\partial \varphi_{0}}{\partial n}\right|_{S_{a}} \quad \text { on the mean wetted part of Ship_a } \\
\frac{\partial \varphi_{7}}{\partial n}=-\left.\frac{\partial \varphi_{0}}{\partial n}\right|_{S_{b}} \quad \text { on the mean wetted part of Ship_b } \\
\frac{\partial \varphi_{7}}{\partial z}=0 \quad \text { on the sea bottom }
\end{gathered}
$$

Moreover, a radiation condition must be implemented to the boundary value problem, which will be discussed latter.

\subsection{Radiation wave potential}

Radiation waves are generated by the oscillation of the vessel. For linearization, the radiation potential can be written as:

$$
\Psi_{R}(\vec{x}, t)=\operatorname{Re} \sum_{j=1}^{6}\left[\eta_{j}^{a} \varphi_{j}^{a}(x, y, z) e^{-i \omega_{e} t}+\eta_{j}^{b} \varphi_{j}^{b}(x, y, z) e^{-i \omega_{e} t}\right]
$$


$\varphi_{j}^{a}$ and $\varphi_{j}^{b}(j=1,2, \ldots, 6)$ are the spatial radiation potential in six degrees of freedom corresponding to the oscillations of Ship_a and Ship_b respectively and $\eta_{j}(j=1,2, \ldots, 6)$ is the amplitude of the six degrees of motion ( $\eta_{1}$, surge; $\eta_{2}$, sway; $\eta_{3}$, heave; $\eta_{4}$, roll; $\eta_{5}$, pitch; $\eta_{6}$, yaw). The corresponding radiation potential can be obtained by solving the following boundary value problem:

1) Ship_a is oscillating while Ship_b is fixed

$$
\nabla^{2} \varphi_{j}^{a}=0 \quad \text { in the fluid domain }
$$

$$
g \frac{\partial \varphi_{j}^{a}}{\partial z}-\omega_{e}^{2} \varphi_{j}^{a}+2 i \omega_{e} u_{0} \frac{\partial \varphi_{j}^{a}}{\partial x}+u_{0}^{2} \frac{\partial^{2} \varphi_{j}^{a}}{\partial x^{2}}=0 \quad \text { on the undisturbed free surface } S_{f}
$$

$$
\frac{\partial \varphi_{j}^{a}}{\partial n}=-i \omega_{e} n_{j}^{a}+\left.u_{0} m_{j}^{a}\right|_{S_{a}} \quad \text { on the mean wetted part of Ship_a }
$$

$$
\frac{\partial \varphi_{j}^{a}}{\partial n}=\left.0\right|_{S_{b}} \quad \text { on the mean wetted part of Ship_b }
$$

$$
\frac{\partial \varphi_{j}^{a}}{\partial z}=0 \quad \text { on the sea bottom }
$$

\section{2) Ship_b is oscillating while Ship_a is fixed}

$$
\nabla^{2} \varphi_{j}^{b}=0 \quad \text { in the fluid domain }
$$

$$
\begin{gathered}
g \frac{\partial \varphi_{j}^{b}}{\partial z}-\omega_{e}^{2} \varphi_{j}^{b}+2 i \omega_{e} u_{0} \frac{\partial \varphi_{j}^{b}}{\partial x}+u_{0}^{2} \frac{\partial^{2} \varphi_{j}^{b}}{\partial x^{2}}=0 \quad \text { on the undisturbed free surface } S_{f} \\
\frac{\partial \varphi_{j}^{b}}{\partial n}=-i \omega_{e} n_{j}^{b}+\left.u_{0} m_{j}^{b}\right|_{S_{b}} \quad \text { on the mean wetted part of Ship_b } \\
\frac{\partial \varphi_{j}^{b}}{\partial n}=\left.0\right|_{S_{a}} \quad \text { on the mean wetted part of Ship_a } \\
\frac{\partial \varphi_{j}^{b}}{\partial z}=0 \quad \text { on the sea bottom }
\end{gathered}
$$

Besides, a radiation condition must be imposed on the control surface to complete the boundary value problem. The generalized normal vectors are defined as 


$$
n_{j}=\left\{\begin{array}{c}
\vec{n}, j=1,2,3 \\
\vec{x} \times \vec{n}, j=4,5,6
\end{array}\right.
$$

and $\vec{n}=\left(n_{1}, n_{2}, n_{3}\right)$ is the unit normal vector directed inward on body surface, $\vec{x}=(x, y, z)$ is the position vector on body surface. The $m_{j}$ denotes the $j$-th component of the so-called $m$-term, which can be expressed as

$$
m_{j}=\left\{\begin{array}{c}
-(\vec{n} \cdot \nabla) \nabla \varphi_{s}, j=1,2,3 \\
-(\vec{n} \cdot \nabla)\left(\vec{x} \times \nabla \varphi_{s}\right), j=4,5,6
\end{array}\right.
$$

where $\varphi_{s}$ is the steady wave potential. The $m$-terms represent the effects of the steady wave on unsteady flows and involve the second derivatives of the steady potential. However, in the present study, we are interested in low forward speed problem, where the contribution of the steady waves is very small (Kim and Shin, 2007). Therefore, the Neumann-Kelvin linearization can be used to simplify the $m$-terms,

$$
\begin{aligned}
& \left(m_{1}, m_{2}, m_{3}\right)=(0,0,0) \\
& \left(m_{4}, m_{5}, m_{6}\right)=\left(0, n_{3},-n_{2}\right)
\end{aligned}
$$

The radiation condition ensures that the waves propagate away from the ship. Fig. 2 illustrates the Doppler shift of the scattered wave field of single ship advancing in the positive $x$ direction and its effect on the implementation of the radiation condition. When the vessel speed exceeds the group velocity of the scattered waves, a quiescent region emerges ahead. The waves reaching point $D$ have their wave direction rotated by an angle $\theta$ relative to the radial axis and their apparent origin shifted downstream to point $B$. The scattered waves at a large distance from the vessel behave similar to those from a point source, giving rise to the kinematic condition $B O / u_{0}=B D / c$, where $c$ is the velocity of the scattered waves in absence of the current. This relation determines the local wave number $k_{s}$ and rotated angle $\theta$ at any points on the control surface. The radiation condition then can be written as

$$
\begin{gathered}
\frac{\partial \varphi_{j}}{\partial n}-i k_{s} \varphi_{j} \cos \theta=0 \quad(j=1,2, \ldots, 6) \text { on } S_{c 1} \\
\nabla \varphi_{j}=0 \quad(j=1,2, \ldots, 6) \quad \text { on } S_{c 2}
\end{gathered}
$$

where $S_{c 1}$ and $S_{c 2}$ denote the portions of control surface with and without scattered waves (Yuan et al., 2014a).

\section{Equation of motion}

Once the unknown diffraction potential $\varphi_{7}$ and radiation potential $\varphi_{j}$ are solved, the time-harmonic pressure can be obtained from Bernoulli's equation: 


$$
p_{j}=-\rho\left[i \omega_{e} \eta_{j} \varphi_{j}+\nabla\left(\varphi_{s}-u_{0} x\right) \cdot \nabla \eta_{j} \varphi_{j}\right], j=0,1, \ldots, 7
$$

where $\rho$ is the fluid density. The hydrodynamic force produced by the oscillatory motions of the vessel in the six degrees of freedom can be derived from the radiation potentials as

$$
\begin{gathered}
F_{i}^{R a}=\sum_{j=1}^{6} \iint_{S_{a}} p_{j}^{a} n_{i} d S \cdot\left(\eta_{j}^{a}+\eta_{j}^{b}\right)=\sum_{j=1}^{6}\left[\omega_{e}^{2} \mu_{i j}^{a a}+i \omega \lambda_{i j}^{a a}\right] \eta_{j}^{a}+\sum_{j=1}^{6}\left[\omega_{e}^{2} \mu_{i j}^{a b}+i \omega \lambda_{i j}^{a b}\right] \eta_{j}^{b}, \quad i=1,2, \ldots, 6(27) \\
F_{i}^{R b}=\sum_{j=1}^{6} \iint_{S_{b}} p_{j}^{b} n_{i} d S \cdot\left(\eta_{j}^{a}+\eta_{j}^{b}\right)=\sum_{j=1}^{6}\left[\omega_{e}^{2} \mu_{i j}^{b a}+i \omega_{e} \lambda_{i j}^{b a}\right] \eta_{j}^{a}+\sum_{j=1}^{6}\left[\omega_{e}^{2} \mu_{i j}^{b b}+i \omega_{e} \lambda_{i j}^{b b}\right] \eta_{j}^{b}, \quad i=1,2, \ldots, 6(28)
\end{gathered}
$$

The added mass and damping can be expressed respectively as:

$$
\begin{aligned}
& \mu_{i j}^{a a}=-\frac{\rho}{\omega_{e}} \iint_{S_{a}}\left(\varphi_{I j}^{a}-\frac{u_{0}}{\omega_{e}} \frac{\partial \varphi_{R j}^{a}}{\partial x}\right) n_{i} d s \\
& \mu_{i j}^{a b}=-\frac{\rho}{\omega_{e}} \iint_{S_{a}}\left(\varphi_{I j}^{b}-\frac{u_{0}}{\omega_{e}} \frac{\partial \varphi_{R j}^{b}}{\partial x}\right) n_{i} d s \\
& \mu_{i j}^{b b}=-\frac{\rho}{\omega_{e}} \iint_{S_{b}}\left(\varphi_{I j}^{b}-\frac{u_{0}}{\omega_{e}} \frac{\partial \varphi_{R j}^{b}}{\partial x}\right) n_{i} d s \\
& \mu_{i j}^{b a}=-\frac{\rho}{\omega_{e}} \iint_{S_{b}}\left(\varphi_{I j}^{a}-\frac{u_{0}}{\omega_{e}} \frac{\partial \varphi_{R j}^{a}}{\partial x}\right) n_{i} d s \\
& \lambda_{i j}^{a a}=-\rho \iint_{S_{a}}\left(\varphi_{R j}^{a}+\frac{u_{0}}{\omega_{e}} \frac{\partial \varphi_{I j}^{a}}{\partial x}\right) n_{i} d s \\
& \lambda_{i j}^{a b}=-\rho \iint_{S_{a}}\left(\varphi_{R j}^{b}+\frac{u_{0}}{\omega_{e}} \frac{\partial \varphi_{I j}^{b}}{\partial x}\right) n_{i} d s \\
& \lambda_{i j}^{b b}=-\rho \iint_{S_{b}}\left(\varphi_{R j}^{b}+\frac{u_{0}}{\omega_{e}} \frac{\partial \varphi_{I j}^{b}}{\partial x}\right) n_{i} d s \\
& \lambda_{i j}^{b a}=-\rho \iint_{S_{b}}\left(\varphi_{R j}^{a}+\frac{u_{0}}{\omega_{e}} \frac{\partial \varphi_{I j}^{a}}{\partial x}\right) n_{i} d s
\end{aligned}
$$

where $\mu_{i j}^{a a}$ is the added mass of Ship_a in $i$-th mode which is induced by the motion of Ship_a in $j$-th mode; $\mu_{i j}^{a b}$ is the added mass of Ship_a in $i$-th mode which is induced by the motion of Ship_b in $j$-th mode; $\mu_{i j}^{b a}$ is the added mass of Ship $\_$in $i$-th mode which is induced by the motion of Ship $\_$a in $j$-th mode; $\mu_{i j}^{b b}$ is the added mass of Ship_b in $i$-th mode which is induced by the motion of Ship_b in $j$-th mode; $\lambda$ is the added damping and the definition the subscript is the same as that of added mass; $\varphi_{R j}$ is the real part of $j$-th potential, 
and $\varphi_{I j}$ is the imaginary part. The wave excitation force can be obtained by the integration of incident and diffraction pressure as

$$
\begin{aligned}
& F_{i}^{W a}=\iint_{S_{a}}\left(p_{0}+p_{7}\right) n_{i} d S \\
& F_{i}^{W b}=\iint_{S_{b}}\left(p_{0}+p_{7}\right) n_{i} d S
\end{aligned}
$$

Applying Newton's second law, the 12 components of ship motions in the frequency domain can be obtained by solving the following equation system:

$$
\begin{aligned}
& \sum_{j=1}^{6}\left\{\left[-\omega_{e}^{2}\left(M_{i j}^{a}+\mu_{i j}^{a a}\right)+i \omega_{e} \lambda_{i j}^{a a}+K_{i j}^{a}\right] \eta_{j}^{a}+\left[-\omega_{e}^{2} \mu_{i j}^{a b}+i \omega_{e} \lambda_{i j}^{a b}\right] \eta_{j}^{b}\right\}=F_{i}^{W a}, \quad i=1,2, \ldots, 6 \\
& \sum_{j=1}^{6}\left\{\left[-\omega_{e}^{2} \mu_{i j}^{b a}+i \omega_{e} \lambda_{i j}^{b a}\right] \eta_{j}^{a}+\left[-\omega_{e}^{2}\left(M_{i j}^{b}+\mu_{i j}^{b b}\right)+i \omega_{e} \lambda_{i j}^{b b}+K_{i j}^{b}\right] \eta_{j}^{b}\right\}=F_{i}^{W b}, \quad i=1,2, \ldots, 6
\end{aligned}
$$

where $M_{i j}^{a}$ and $M_{i j}^{b}$ represent the generalized mass matrix for Ship_a and Ship_b; $K_{i j}^{a}$ and $K_{i j}^{b}$ represent the restoring matrix for Ship_a and Ship_b. The mass and restoring force matrix can be given by

$$
\begin{gathered}
M_{i j}=\left[\begin{array}{cccccc}
m & 0 & 0 & 0 & m z_{G} & 0 \\
0 & m & 0 & -m z_{G} & 0 & m x_{G} \\
0 & 0 & m & 0 & -m x_{G} & 0 \\
0 & -m z_{G} & 0 & I_{44} & 0 & I_{46} \\
m z_{G} & 0 & -m x_{G} & 0 & I_{55} & 0 \\
0 & m x_{G} & 0 & I_{64} & 0 & I_{66}
\end{array}\right] \\
K_{i j}=\left[\begin{array}{ccccccc}
0 & 0 & 0 & 0 & 0 & 0 \\
0 & 0 & 0 & 0 & 0 & 0 \\
0 & 0 & \rho g A_{w} & 0 & -\rho g M_{w} & 0 \\
0 & 0 & 0 & \rho g\left(I_{w 1}+V z_{B}\right) & 0 & 0 \\
0 & 0 & -\rho g M_{w} & 0 & \rho g\left(I_{w 2}+V z_{B}\right) & 0 \\
0 & 0 & 0 & 0 & 0 & 0
\end{array}\right]
\end{gathered}
$$

where $m$ is the body mass; $\left(x_{G}, y_{G}, z_{G}\right)$ is the center of gravity; $I_{44}, I_{55}$ and $I_{66}$ are the roll, pitch and yaw moments of inertia; the roll-yaw moment of inertia holds the symmetry relation $I_{46}=I_{64} ; A_{w}$ is the water plane area; $M_{w}$ is the first moment of the water plane about the y-axis; $I_{w l}$ and $I_{w 2}$ are the second moments of the water plane about the $x$-axis and $y$-axis respectively; $V$ is the underwater volume; $z_{B}$ is the vertical centre of buoyancy. The standard matrix solution routine provides the complex amplitude of the oscillatory motions 
from Eqs. (33)-(34). The wave elevation on the free surface then can be obtained from the dynamic free surface boundary condition in the form

$$
\zeta_{j}=\frac{i \omega_{e}}{g}\left(\eta_{j}^{a} \varphi_{j}^{a}+\eta_{j}^{b} \varphi_{j}^{b}\right)+\frac{1}{g} \nabla\left(\varphi_{s}-u_{0} x\right) \cdot \nabla\left(\eta_{j}^{a} \varphi_{j}^{a}+\eta_{j}^{b} \varphi_{j}^{b}\right)=\zeta_{R j}+i \zeta_{I j}, \quad j=0,1, \ldots, 7
$$

where $\zeta_{R j}$ is the real part of $j$-th model, and $\zeta_{I j}$ is the imaginary part.

\section{Numerical implementation}

\subsection{Discretization of the boundary integral}

In the numerical study, the boundary is divided into a number of quadrilateral panels with constant source

density $\sigma(\vec{\xi})$, where $\vec{\xi}=(\xi, \eta, \varsigma)$ is the position vector on the boundary. If $\vec{x}=(x, y, z)$ is inside the fluid domain or on the boundary surface, the potential can be expressed by a source distribution on the boundary of the fluid domain:

$$
\varphi(\vec{x})=\iint_{S_{b}+S_{f}+S_{c}} \sigma(\vec{\xi}) G(\vec{x}, \vec{\xi}) d S_{\xi}
$$

where $\varphi$ denotes the steady potential $\varphi_{s}$ or the unsteady potential $\varphi_{j}, G(\vec{x}, \vec{\xi})$ is the Rankine-type Green function that satisfies the sea bed boundary condition through the method of mirror image

$$
G(\vec{x}, \vec{\xi})=\frac{1}{\sqrt{(x-\xi)^{2}+(y-\eta)^{2}+(z-\varsigma)^{2}}}+\frac{1}{\sqrt{(x-\xi)^{2}+(y-\eta)^{2}+(z+2 d+\varsigma)^{2}}}
$$

If we have $N$ panels on the body surface, free surface and control surface together, the potential in point $\vec{x}$ becomes

$$
\varphi\left(\vec{x}_{i}\right)=\sum_{j=1}^{N} \frac{\sigma_{j}}{4 \pi} \iint_{S_{b}+S_{f}+S_{c}} G\left(\vec{x}_{i}, \vec{\xi}\right) d S_{\xi}=\sum_{j=1}^{N} \frac{\sigma_{j}}{4 \pi} G_{i, j}
$$

When the collocation point and the panel are close to each other, the influence coefficients $G_{i, j}$ can be calculated with analytical formulas listed by Prins (1995) when the distance between the collocation point and the panel is large, these coefficients are calculated numerically. The same procedure can be applied to discretize the boundary integral for the velocity

$$
\frac{\partial \varphi}{\partial n}\left(\vec{x}_{i}\right)=\frac{1}{2} \sigma_{i}+\sum_{\substack{j=1 \\ j \neq i}}^{N} \frac{\sigma_{j}}{4 \pi} \iint_{S_{b}+S_{f}+S_{c}} \frac{\partial}{\partial n_{i}} G\left(\vec{x}_{i}, \vec{\xi}\right) d S_{\xi}=\frac{1}{2} \sigma_{i}+\sum_{\substack{j=1 \\ j \neq i}}^{N} \frac{\sigma_{j}}{4 \pi} G_{i, j}^{n}
$$


The analytical formulas of the influence coefficients $G_{i, j}^{n}$ are listed by Hess and Smith (1964).

\subsection{Desingularied method}

The singularity distribution does not have to be located on the free surface itself, it can also be located at a short distance above the free surface, as long as the collocation points, where the boundary condition has to be satisfied, stay on the free surface. In practice, a distance of maximal three times the longitudinal size of a panel is possible (Bunnik, 1999). In the present study, the raised distance $\Delta z_{i}=0.25 \sqrt{S_{i}}$, where $S_{i}$ is the area of the $i$-th panel.

Special attentions should be paid on the second derivative of the potential on the free surface. Generally, the difference schemes can be divided in two classes: upwind difference schemes and central difference schemes. Although central difference schemes are supposed to be more accurate, the stabilizing properties of the upwind difference schemes are more desired in the forward speed problem (Bunnik, 1999). Physically this can be explained by the face that new information on the wave pattern mainly comes from the upstream side, especially at high speeds, whereas the downstream side only contains old information. For the steady wave problem, as demonstrated by Kim et al. (2005), the second order upwind scheme is recommended to minimized the numerical dispersion and damping when the constant panel method is used. However, the unsteady wave length is usually much larger than the steady wave length. As long as the panel size is small enough, the numerical damping and dispersion due to the difference scheme can be restrained at a very small level. In the present study, we distribute around 60 panels at each ship length. According to Kim's study (Kim et al., 2005), even the first-order upwind scheme can provide a satisfactory results. Therefore, in our numerical program, the three points upwind difference scheme is used to obtain the second derivative of the potential to $x$ :

$$
\frac{\partial^{2} \varphi}{\partial x^{2}}\left(\vec{x}_{i}\right)=\frac{1}{\Delta x^{2}}\left[\varphi\left(\vec{x}_{i+2}\right)-2 \varphi\left(\vec{x}_{i+1}\right)+\varphi\left(\vec{x}_{i}\right)\right]
$$

\section{Validations and discussion}

The method described above is included in our in-house developed multi-body hydrodynamic interaction program MHydro to investigate the hydrodynamic interaction between two ships travelling or stationary in shallow water. The validations are established through a series of numerical experiments. For the stationary case, there are two case studies: two Wigley hulls at head sea condition; a Wigley and a rectangular box at beam sea condition. For the ship-to-ship with forward speed case, a tanker-LNG ship model will be studied and Ronæss' experiments (Ronæss, 2002) will provide the motion responses for the validation. 


\subsection{Validations of two ships stationary in waves}

The Wigley III hulls used in the present study can be defined as

$$
y=\frac{B}{2}\left[1-\left(\frac{z}{D}\right)^{2}\right]\left[1-\left(\frac{2 x}{L}\right)^{2}\right]\left[1+0.2\left(\frac{2 x}{L}\right)^{2}\right]
$$

The main particulars of Wigley III model are shown in Table 1. The panels of the computational domain is shown in Fig. 3. Fig. 4 shows the wave excitation forces and the response amplitudes of two ships in sway, roll and yaw directions. Very satisfactory agreement is achieved between the present method and Wadam solution (2010). For the present 3-D Rankine source method, 13700 panels are distributed on the body-, freeand control-surface, while only 2000 panels on the body surface are required for the Wadam program which is based on the frame work of 3-D Green function. Therefore, more CPU time is consumed by the present program on modelling as well as solving a very large full rank matrix. It can be concluded that both Rankine source method and Green function method can provide a stable solution for the ship-to-ship with zero speed problem. The advantage of the present method should be concentrated on the two ships travelling with forward speed in the restricted waters, which will be discussed later. A very large sway force can be observed in Fig. 4 (a) at $\lambda / L=0.25$. This force is very undesirable during offloading operation. The large separating force could break the mooring lines between two vessels, while the attraction force could make the vessels collide with each other. The peak value of roll motion in Fig. 4 (b) can be found around $\lambda / L=0.65$, which corresponds to the nature frequency of roll motion. We also find that there are some spikes in roll moment in Fig. 4 (c). The first spike appears at $\lambda / L=0.33$, which corresponds to the wave length that equals to the transverse distance $d t(L=3 \mathrm{~m}, d t=1 \mathrm{~m})$. Similarly, the second and third spikes arise at $\lambda / L=0.66$ and $\lambda / L$ $=1$, which correspond to the wave length that equals to $2 d t$ and $3 d t$ respectively.

We also calculated the hydrodynamic interaction between a Wigley hull (Ship_a) and a rectangular box (Ship_b) at beam sea condition. The main particulars of the Wigley hull and the box are shown in Table 2 . The panels of the computational domain is shown in Fig. 5. Two typical cases are simulated here:

1) Ship_a is situated in the weather side and Ship_b is in the lee side. The transverse $(d t)$ and longitudinal distance $(d l)$ between the two ships is $1.097 \mathrm{~m}$ and $0 \mathrm{~m}$ respectively.

2) Ship_a is situated in the lee side and Ship_b is in the weather side. The transverse $(d t)$ and longitudinal distance $(d l)$ between the two ships is $1.797 \mathrm{~m}$ and $0 \mathrm{~m}$ respectively.

Fig. 6 shows the hydrodynamic coefficients of the Wigley hull due to the heave motion of the Wigley hull itself when the rectangular box is fixed with the separation distance of $d t=1.797 \mathrm{~m}$, where $K=\omega_{0}^{2} L_{c} / g$ and $L_{c}$ is the characteristic length scale for nondimension (which is taken as $L_{c}=L_{a} / 2$ ). The comparisons with experimental data and Green function method (Kashiwagi et al., 2005) are also included. The numerical results calculated by the present 3-D Rankine source method generally agree well with the experimental data. 
The hydrodynamic interactions are properly accounted for, especially in the sway added mass and damping ( $\mu_{23}^{a a}$ and $\lambda_{23}^{a a}$ ) which are exerted only by wave interactions between the Wigley hull and the box. Some discrepancies can be observed in the heave added mass and damping ( $\mu_{33}^{a a}$ and $\left.\lambda_{33}^{a a}\right)$ at low frequency range, which could be attributed to the effect of the reflection waves from the parallel side walls of the tank, as explained by Kashiwagi et al. (2005). Fig. 7 shows the wave excitation forces on the modified Wigley hull (in the weather side) and rectangular box (in the lee side) with the separation distance of $d t=1.097 \mathrm{~m}$. The overall agreement between measured and computed results is good, although slight discrepancies can be seen in a range of long wavelengths, which is due to the reflection wave effects from the side walls of the towing tanker. Very good agreement has been obtained between the present Rankine source method and Green function method. It can be concluded that both Green function method and Rankine source method can predict the hydrodynamic forces of two ships arranged side by side with zero speed in beam waves.

\subsection{Validations of two different ships with forward speed}

The main particulars of tanker (Ship_a) and LNG (Ship_b) are shown in Table 3. The details of model test setup is elaborated by Ronæss (2002). She analysed the bias sources and carried out comparative study. He found that the experimental setup corrections were necessary and in the present calculation, such corrections will be used, as shown in Table 4. The forced roll centre is taken to be $0.032 \mathrm{~m}$ below the mean water level for Ship_a and $0.104 \mathrm{~m}$ above the mean water level for Ship_b. To be consistent with the model tests condition, Ship_a is restrained in surge and sway while the motions in heave, roll, pitch and yaw are free; Ship_b is restrained in surge, sway and yaw while the other degrees of freedom are set free. Two typical cases are studied here to simulate the different configurations of ship-to-ship problem. In Case 1, the transverse and longitudinal distances between two ships are $1.25 \mathrm{~m}$ and $0.09 \mathrm{~m}$ respectively, which indicates that the longitudinal centre of these two ships are approximately the same. In Case 2, the longitudinal centre of two ships is staggered and the transverse and longitudinal distances between two ships are $1.25 \mathrm{~m}$ and $0.59 \mathrm{~m}$ respectively. Both cases are in head sea condition with forward speed of $0.608 \mathrm{~m} / \mathrm{s}\left(F n=u_{0} / \sqrt{g L_{a}}=0.1\right)$. In order to make comparison, we also present the results of single ship with the same forward speed and two ships at zero forward speed. The computational domain of Case 1 is shown in Fig. 8.

\subsubsection{Motion responses}

Fig. 9 and Fig. 10 are the response amplitudes of Case 1 and Case 2 respectively. The comparisons with the experimental data and the unified theory are also included. The present results in heave and pitch motion of both ships generally have a satisfactory agreement with those of experimental data. A remarkable discrepancy in Case 1 can be observed in Fig. 9 (a) and Fig. 9 (e) at $\lambda / L_{a}=1.2$ and $\lambda / L_{a}=1.3$, which corresponds to the resonant frequency of heave and pitch of Ship_a respectively. Such discrepancy can also be observed in Case 2 from Fig. 10 (a) and Fig. 10 (e). But the resonant frequency in the numerical calculation is around at $\lambda / L_{a}=$ 
1 for both heave and pitch of Ship_a. This difference is attributed to the trim suspensions in the model test setup (Ronæss, 2002). When it comes to the roll motion, the present prediction, as well as Ronæss' (2002) calculation, is not satisfactory. The main reason for the discrepancies is about the damping coefficient. According to Ronæss (2002), the roll viscous damping of Ship_a is taken as $\lambda_{44 v}=2 \lambda_{44}$ for the forward speed case and $\lambda_{44 v}=\lambda_{44}$ for the zero speed case. For Ship_b, it is taken as $\lambda_{44 v}=6 \lambda_{44}$ for the forward speed case and $\lambda_{44 v}=4 \lambda_{44}$ for the zero speed case. The lift damping is another factor, which will increase when the roll centre is above the mean water level (Himeno, 1981). Besides, the measurement of roll motions from the model test is full of challenges. The devices used to measure the roll motion could bring additional friction and upward forces, as demonstrated by Ronæss (2002). In order to investigate the speed effect, the results of two ships without forward speed are presented. It is found that the increase of the response amplitude operators with forward speed is considerable for both Case 1 and Case 2. We also include the results of single ship with forward speed. From the comparison, we find that the hydrodynamic interaction has much greater influence on the motions of the smaller ship. For heave and pitch motion of the larger ship (Ship_a), the influence from the smaller ship (Ship_b) is not noticeable. But the hydrodynamic interaction is the essential reason that induces the roll motion for both ships. There is no roll motion in head sea condition for a single ship due to the symmetrical characteristics.

\subsubsection{Hydrodynamic coefficients}

Fig. 11 and Fig. 12 are the non-dimensional added mass and damping coefficients respectively. The first comparison should be made from the added mass and damping of Ship_a. The hydrodynamic coefficients of Ship_a are composed of two components, the self-induced component (labelled as aa at its superscript, e.g. $\mu_{i j}^{a a}$ ) and the external-induced component (labelled as $a b$ at its superscript, e.g. $\mu_{i j}^{a b}$ ). From Fig. 11 (a)-(d) and Fig. 12 (a)-(d), we find the self-induced hydrodynamic coefficients of Ship_a are much greater than the external-induced ones, which indicates that the hydrodynamic coefficients of Ship_a are mainly determined by the oscillation of Ship_a itself. The hydrodynamic coefficients of Ship_a induced by the oscillation of Ship_b are not noticeable compared to the self-induced component. This can explain why the hydrodynamic interaction has less influence on the motion responses of the larger ship in Fig. 9 (a), (e) and Fig. 10 (a), (e). But when it comes to the hydrodynamic coefficients of Ship_b, the self-induced and external-induced components are at the same level. This can explain why the hydrodynamic interaction has much greater influence on the motions of the smaller ship in Fig. 9 (b), (f) and Fig. 10 (b), (f). Special attention should be paid on the roll added mass and damping. Since the models are restrained in surge and sway (Ship_b is also restrained in yaw), the roll added mass is mainly composed of roll-induced, heave-induced and pitch-induced components, which are shown in Fig. 11 (d), (e) and (f) respectively. It is very interesting to find that the main contribution to the roll added mass comes from the heave-induced component, while the contribution from the roll-induced component is very small. It is not the case for heave added mass. As can be seen from Fig. 11 (a) and (b) that the heave-induced heave added mass is much greater than the pitch-induced heave added mass. It can also be observed from Fig. 11 (d)-(f) and Fig. 12 (d)-(f) that the non-dimensional roll added mass and 
damping of Ship_b due to the roll motion of Ship_a is very large, especially in heave-induced and pitchinduced components. This explains why the hydrodynamic interaction brings a greater influence on the roll motion of the smaller ship, as shown in Fig. 9 (c)-(d) and Fig. 10 (c)-(d).

\subsubsection{Wave excitation forces}

Fig. 13 gives the non-dimensional wave excitation forces in sway and roll directions on both ships in Case 1 . Two large spikes can be observed in Fig. 13 (a) and (b) for the zero speed cases of both ships at $\lambda / L_{a}=0.33$, which corresponds to the wave length that equals to the transverse distance between two ships. At this wave length, the sway force, as well as the roll moment, can reach an extreme value, which is not desirable during the offloading operation. We also investigate the wave elevation at $\lambda / L_{a}=0.33$, which is shown in Fig. 15 . Since the scattered waves are trapped in the small gap and cannot propagate to the far field, the wave elevation in the gap between two ships can also achieve a considerable value. In this case, the ship-to-ship offloading operation will be at great risks. On the one hand, the large sway force will bring a huge separating load on the mooring lines between the two vessels; on the other hand, the large wave elevation in the gap will cause the green water problem, especially for the smaller ship with small freeboard. This phenomenon has also been observed by the researches in their studies about the moon pool (Faltinsen et al., 2007; Molin, 2001). But in the forward speed cases, there is no large spike at $\lambda / L_{a}=0.33$. This is because the Doppler shift modifies the wave length according to the propagation direction, and the scattered waves can escape from the gap. It can also be observed in Fig. 13 (b) that the non-dimensional roll moment on Ship_b is much greater than that on Ship_a. This can explain why the roll motion amplitude of Ship_b is much greater than that of Ship_a, which is shown in Fig. 9 (c)-(d) and Fig. 10 (c)-(d). Comparing the results of the heave force and pitch moment on Ship_a in Fig. 14 (a) and (c), we find the difference between the single and two ships with forward speed is not significant, which can explain why the motion responses of a single ship with forward speed are quite close to that of two ships' case, as shown in Fig. 9 (a), (e) and Fig. 10 (a), (e). From Fig. 14 (b) and (d), we find the curves of the forces on Ship_b without interaction are smoother. Some fluctuations can be observed when Ship_a is in presence. A sudden increase of heave force on Ship_b at $\lambda / L_{a}=1.5$ can be found in Fig. 14 (b) for two ships with speed case, which results in an increase in heave motion as shown in Fig. 9 (b), while a drop of pitch moment at $\lambda / L_{a}=1.5$ in Fig. 14 (d) can give an explain why the pitch motion experience a decrease at $\lambda / L_{a}=1.5$ in Fig. 9 (f).

Fig. 15 shows the wave elevation of two ships without forward speed at $\lambda=1.25 \mathrm{~m}$, which corresponds to $\lambda$ / $L_{a}=0.33$. The wave elevation is non-dimensionalized by the incident wave amplitude $\eta_{0}$. The contour lines of the wave elevation in the gap between the two ships are presented on the top of each figure. The total wave elevation is composed of incident, diffraction and radiation components. Since the models are restrained in surge and sway (Ship_b is also restrained in yaw), the radiation component is mainly from the oscillation of heave, roll and pitch. From Fig. 9 we can find the motion amplitudes at $\lambda / L_{a}=0.33$ are very small and the corresponding radiated wave amplitude should also be at a small level. Therefore, the incident and diffraction components contribute for the major parts. In can be observed in Fig. 15 (a) that the diffracted wave elevation 
in the gap is much higher than that outside the gap, which indicates that most of the diffracted wave energy is trapped in the gap. These trapped waves will inevitably induce an extremely inhomogeneous wave loads on both ships, which explains the enormous sway force and roll moment in Fig. 13 (a) and (b). Meanwhile, from Fig. 15 (b) we can also find that the longitudinal distribution of the wave elevation along Ship_b is not balanced. As a consequence, a yaw moment will be induced, which could produce a very large yaw motion.

\subsubsection{Effect of shallow water}

The Green function method is regarded as an effective solution for the marine vessels without speed in deep waters. When it refers to the shallow water associated with the forward speed problem, the Green function becomes very complicated. However, the present Rankine source method can provide an intuitive solution for this issue. It takes account of the forward speed into the boundary value problem and the Rankine-type Green function can satisfy the seabed boundary condition through the method of image in Eq. (39). Fig. 16 shows the motion responses of both ships at different water depths. The parameters of Case 1 are used here with $F_{n}=0.1$ and $d l=0.09 \mathrm{~m}$. From the figures it can be seen that the water depth has a significant influence on the responses of both ships. Both of the amplitudes and resonance frequencies are changed by the water depth. There are mainly two reasons for these discrepancies. The first reason is that the shallow water dispersion relation in Eq. (4) changes the incident wave length and as a result, the wave exciting forces and the resonance frequencies differ from those in deep water. It can be observed that at small $\lambda / L_{\mathrm{a}}$, the difference is very small. As $\lambda / L_{\mathrm{a}}$ increases, the discrepancies tend to be very large. The results in Fig. 17 can explain this phenomenon. The $x$-axis of Fig. 17 is the non-dimensional incident wave length, where $\lambda_{0}$ is the wave length in infinite water depth. We find at small $\lambda / L_{\mathrm{a}}$, the wave length at different water depths differs a little. The difference keeps a similar increase trend with that of motion responses in Fig. 16 as $\lambda / L_{\mathrm{a}}$ increases. The second reason is the hydrodynamic coefficients and diffraction forces of the ship are changed by the nearness of the sea bottom. As can be seen from Fig. 18, the diffracted wave pattern in shallow water differs a lot from that in infinite water. Since $\lambda / L_{\mathrm{a}}$ is fixed at 1 , the wave trough arises around bow area, while the wave crest arises around the stern. This is the most unfavourable load case, since both the heave force and pitch moment achieves a maximum value. As a consequence, the motion responses in heave and pitch reach their peaks around $\lambda / L_{\mathrm{a}}=$ 1, which can be observed in Fig. 16 (a) and (e). At $\lambda / L_{\mathrm{a}}=1$, the heave force on Ship_a is mainly determined by the wave elevation. It can be seen from Fig. 18 that the diffracted wave elevation in deep water is much larger than that in shallow water, which explains why heave motion of Ship_a in deep water is greater than that in shallow as shown in Fig. 16 (a). The roll moment mainly comes from the pressure difference at portside and starboard of the ships. We find in deep water, the wave crest around the stern is asymmetric. As a consequence, the roll motion should be significant. But in shallow water, a better symmetrical wave pattern presents at portside and starboard of Ship_a. This can explain why the roll motion at $\lambda / L_{\mathrm{a}}=1$ in deep water is much greater than that in shallow water. 


\section{Conclusions}

In this paper, a boundary element program, MHydro, which is based on 3-D Rankine source method is developed to investigate the ship-to-ship interaction with or without forward speed problem. The radiation condition is satisfied by a modified Sommerfield radiation condition that takes Doppler shift into account while the Rankine-type Green function can satisfy the seabed boundary condition through the method of image. In order to eliminate the singularity on the free surface, we raise the source point at a short distance above the calm water level.

We validated the present program through a series of models travelling or stationary in waves. For the ship-toship without speed problem, we examined our method through the commercial software, as well as the model test results. The case studies involved in two identical ships and two different ships both in head and beam sea conditions. The validation was established on the comparison between the present Rankine source method and Green function solution, as well as the experimental results. Good agreement has been achieved. The present method turned to be more time-consuming due to the modelling and solving the huge full rank matrix. However, the advantage of the present method lies on the two ships travelling with forward speed in the restricted waters, which was validated through another case study about two different ships advancing in waves. We compared the present calculation with the experimental data and found that the present prediction of heave and pitch motions had a satisfied agreement with the published experimental data. However, the prediction of roll motion not satisfactory due to the inviscid assumption in the potential flow theory, as well as the model test set-up.

We investigated the hydrodynamic interactions through the hydrodynamic coefficients and wave excitation forces. It is found that the hydrodynamic coefficients of the larger ship are mainly determined by the oscillation of the larger ship itself, while the self-induced and external-induced components of the hydrodynamic coefficients are at the same level for the smaller ship. This can explain why the hydrodynamic interaction has much greater influence on the motions of the smaller ship. We also observed a very large sway force for zero speed case when the transverse distance between two ships equals to the wave length. This extreme force is due to the diffracted wave energy that trapped in the gap and it will bring a great risk to the ship-to-ship offloading operation.

We also discussed the shallow water effects in the ship-to-ship with forward speed problem. It is found that the influence of shallow water effect is significant and requires special attention in the design and operation of two ships travelling with forward speed. 


\section{Acknowledgments}

The work reported in this paper was performed within the project "Energy Efficient Safe Ship Operation (SHOPERA)" funded by the European commission under contract No. 605221. The first author is also supported by Lloyd's Register Marine Division.

\section{References}

Bunnik, T., 1999. Seakeeping calculations for ships, taking into account the non-linear steady waves, PhD thesis. Delft University of Technology, The Netherlands.

Chen, G.R., Fang, M.C., 2001. Hydrodynamic interactions between two ships advancing in waves. Ocean Engineering 28, 1053-1078.

Das, S., Cheung, K.F., 2012. Scattered waves and motions of marine vessels advancing in a seaway. Wave Motion 49 (1), 181-197.

Faltinsen, O.M., Rognebakke, O.F., Timokha, A.N., 2007. Two-dimensional resonant piston-like sloshing in a moonpool. Journal of Fluid Mechanics 575, 359.

Fang, M.C., Kim, C.H., 1986. Hydrodynamically coupled motions of two ships advancing in oblique waves. Journal of Ship Research 30 (3), 159-171.

Hess, J.L., Smith, A.M.O., 1964. Calculation of nonlifting potential flow about arbitrary three-dimensional bodies. Journal of Ship Research 8 (2), 22-44.

Himeno, Y., 1981. Prediction of ship roll damping-state of the art, Report No.239. Department of Naval Architecture and Marine Engineering, University of Michigan.

Jensen, G., Mi, Z.X., Söding, H., 1986. Rankine source methods for numerical solutions of steady wave resistance problem, Proceedings of 16th Symposium on Naval Hydrodynamics, Berkeley, pp. 575-582.

Kashiwagi, M., Endo, K., Yamaguchi, H., 2005. Wave drift forces and moments on two ships arranged side by side in waves. Ocean Engineering 32 (5-6), 529-555.

Kim, B., Shin, Y., 2007. Steady flow approximations in 3-D ship motion calculation. Journal of Ship Research 51 (3), 229-249.

Kim, M.S., Ha, M.K., 2002. Prediction of motion responses between two offshore floating structures in waves. Journal of Ship \& Ocean Technology 6 (3), 13-25.

Kim, Y., Yue, D.K.P., Connell, B.S.H., 2005. Numerical dispersion and damping on steady waves with forward speed. Applied Ocean Research 27 (2), 107-125.

Kodan, N., 1984. The motions of adjacent floating structures in oblique waves, Proceedings of the 3rd International Conference on Offshore Mechanics and Arctic Engineering, New Orleans, pp. 206-213.

Lee, C.H., Sclavounos, P.D., 1989. Removing the irregular frequencies from integral equations in wavebody interactions. Journal of Fluid Mechanics 207, 393-418.

Li, L., 2007. Numerical seakeeping simulation of model test condition for two-ship interaction in waves, Proceedings of the 26th International Conference on Offshore Mechanics and Arctic Engineering, San Diego, California, USA, pp. OMAE2007-29328.

McTaggart, K., Cumming, D., Hsiung, C.C., Li, L., 2003. Seakeeping of two ships in close proximity. Ocean Engineering 30 (8), 1051-1063.

Molin, B., 2001. On the piston and sloshing modes in moonpools. Journal of Fluid Mechanics 430, 27-50.

Nakos, D.E., 1990. Ship wave patterns and motions by a three dimensional Rankine panel method, PhD Thesis. MIT.

Nossen, J., Grue, J., Palm, E., 1991. Wave forces on three-dimensional floating bodies with small forward speed. Journal of Fluid Mechanics 227, 135-160.

Ohkusu, M., 1974. Ship motions in vicinity of a structure, Proceeding of International Conference on Behaviour of Offshore Structure, NIT,Trondheim, pp. 284-306.

Prins, H.J., 1995. Time domain calculations of drift forces and moments, PhD Thesis. Delft University of Technology, The Netherlands.

Ronæss, M., 2002. Wave induced motions of two ships advancing on parallel course, PhD Thesis. NTNU. Wadam, 2010. Wave analysis by diffraction and Morison theory, Version $8.2 \mathrm{ed}$. 
$\mathrm{Xu}$, X., Faltinsen, O.M., 2011. Time domain simulation of two interacting ships advancing parallel in waves, Proceedings of the 30th International Conference on Offshore Mechanics and Arctic Engineering, Rotterdam, The Netherlands, pp. OMAE2011-49484.

$\mathrm{Xu}, \mathrm{Y}$., Dong, W.C., 2013. Numerical study on wave loads and motions of two ships advancing in waves by using three-dimensional translating-pulsating source. Acta Mechanica Sinica 29 (4), 494-502.

Yuan, Z.-M., Incecik, A., Alexander, D., 2014a. Verification of a new radiation condition for two ships advancing in waves. Applied Ocean Research 48, 186-201.

Yuan, Z.-M., Incecik, A., Jia, L., 2014b. A new radiation condition for ships travelling with very low forward speed. Ocean Engineering 88 (0), 298-309. 


\section{Caption of the figures}

Fig. 1 An example vessels and coordinate system

Fig. 2 Sketch of Doppler shift and radiation condition of single ship

Fig. 3 Computational domain of two Wigley hulls in head wave. The free surface is truncated at $1.33 \mathrm{~L}$ upstream, $1.33 \mathrm{~L}$ downstream and $2 L$ sideward. There are 600 panels on the each body surface, 10400 on free surface and 2100 on the control surface.

Fig. 4 (a) Sway force; (b) sway motion; (c) roll moment; (d) roll motion; (e) yaw moment; (f) yaw motion. -, the present prediction from MHydro; $\odot$, numerical results from Wadam (2010).

Fig. 5 Computational domain of the Wigley-Box model in head wave. The free surface is truncated at $2 L_{a}$ upstream, $2 L_{a}$ downstream and $2 L_{a}$ sideward. There are 320 panels on the body surface of Wigley hull, 480 on the body surface of the rectangular box, 7800 on free surface and 2052 on the control surface.

Fig. 6 Hydrodynamic coefficients of a modified Wigley hull due to the heave motion of the Wigley hull itself when the rectangular box is fixed with the separation distance of $d t=1.797 \mathrm{~m}$. (a) Heave-induced heave added mass; (b) heave-induced heave damping; (c) heave-induced sway added mass; (d) heave-induced sway damping. - , the present prediction from MHydro; $\circ$, experimental results from Kashiwagi (2005); --, numerical results based on Green function method (Kashiwagi et al., 2005).

Fig. 7 Wave excitation forces in beam waves with the transverse distance between two ships of $d t=1.097 \mathrm{~m}$. (a) Sway forces on Wigley hull; (b) sway forces on Box; (c) heave forces on Wigley hull; (d) heave forces on Box. -, the present prediction from MHydro; $\circ$, experimental results from Kashiwagi (2005); --, numerical results based on Green function method (Kashiwagi et al., 2005).

Fig. 8 Computational domain of tanker-LNG ship model with forward speed in head waves. The free surface is truncated at $1.05 L_{a}$ upstream, $1.84 L_{a}$ downstream, $1.05 L_{a}$ in the tanker sideward and $1.3 L_{b}$ in the LNG ship sideward. There are 420 panels on the body surface of tanker, 9020 on free surface, 2464 on the control surface and 420 on the body surface of LNG ship.

Fig. 9 Response amplitude operators of Case 1. (a) Heave of ship_a; (b) heave of Ship_b; (c) roll of ship_a; (d) roll of Ship_b; (e) pitch of ship_a; (f) pitch of Ship_b.

Fig. 10 Response amplitude operators of Case 2. (a) Heave of ship_a; (b) heave of Ship_b; (c) roll of ship_a; (d) roll of Ship_b; (e) pitch of ship_a; (f) pitch of Ship_b.

Fig. 11 Added mass. (a) Heave added mass induced by heave motion; (b) heave added mass induced by pitch motion; (c) pitch added mass induced by pitch motion; (d) roll added mass induced by roll motion; (e) roll added mass induced by heave motion; (f) roll added mass induced by pitch motion.

Fig. 12 Damping. (a) Heave damping induced by heave motion; (b) heave damping induced by pitch motion; (c) pitch damping induced by pitch motion; (d) roll damping induced by roll motion; (e) roll damping induced by heave motion; (f) roll damping induced by pitch motion.

Fig. 13 (a) Sway forces; (b) roll moments.

Fig. 14 (a) Heave force on Ship_a; (b) heave force on Ship_b; (c) pitch moment on Ship_a; (d) pitch moment on Ship_b.

Fig. 15 Wave elevation of two ships without speed at $\lambda=0.33 L_{a}=d t$. (a) Real part of diffracted waves; (b) real part of total wave elevation.

Fig. 16 Response amplitude operators of different depths at $F_{n}=0.1$. (a) Heave of ship_a; (b) heave of Ship_b; (c) roll of ship_a; (d) roll of Ship_b; (e) pitch of ship_a; (f) pitch of Ship_b.

Fig. 17 Wave length at different water depths.

Fig. 18 Real part of the diffracted waves at $\lambda / L_{a}=1, F_{n}=0.1$. (a) Infinite water; (b) Shallow water at $d / T_{a}=2$. 
Table 1

Main particulars of Wigley III hull

\begin{tabular}{lr} 
Length, $L(\mathrm{~m})$ & 3 \\
Breadth, $B(\mathrm{~m})$ & 0.3 \\
Draught, $D(\mathrm{~m})$ & 0.1875 \\
Transverse distance between two vessels, $d t(\mathrm{~m})$ & 1 \\
Displacement, $V\left(\mathrm{~m}^{3}\right)$ & 0.078 \\
Centre of rotation above base, $K R(\mathrm{~m})$ & 0.1875 \\
Centre of gravity above base, $K G(\mathrm{~m})$ & 0.17 \\
Radius of inertia for pitch, $k_{y y}(\mathrm{~m})$ & 0.75 \\
\hline
\end{tabular}

Table 2

Main dimensions of the modified Wigley hull and the box (Kashiwagi et al., 2005)

\begin{tabular}{lcc} 
& Modified Wigley hull & Rectangular box \\
\hline Length between perpendicular & $L_{a}=2 \mathrm{~m}$ & $L_{b}=2 \mathrm{~m}$ \\
Breadth & $B_{a}=0.3 \mathrm{~m}$ & $B_{b}=0.3 \mathrm{~m}$ \\
Draught & $T_{a}=0.125 \mathrm{~m}$ & $T_{b}=0.125 \mathrm{~m}$ \\
Displacement & $V_{a}=0.04205 \mathrm{t}$ & $V_{b}=0.075 \mathrm{t}$ \\
Water-plane area & $A_{w a}=0.416 \mathrm{~m}^{2}$ & $A_{w b}=0.60 \mathrm{~m}^{2}$ \\
\hline
\end{tabular}

Table 3

Main particulars of tanker and LNG ship (Ronæss, 2002)

\begin{tabular}{lcc}
\hline & Tanker & LNG ship \\
\hline Length between perpendicular & $L_{a}=3.76 \mathrm{~m}$ & $L_{b}=2.28 \mathrm{~m}$ \\
Breadth & $B_{a}=0.625 \mathrm{~m}$ & $B_{b}=0.387 \mathrm{~m}$ \\
Draught & $T_{a}=0.232 \mathrm{~m}$ & $T_{b}=0.124 \mathrm{~m}$ \\
Displacement & $V_{a}=0.4355 \mathrm{t}$ & $V_{b}=0.074 \mathrm{t}$ \\
Block coefficient & $C_{B}^{a}=0.83$ & $C_{B}^{b}=0.68$ \\
Water plane area coefficient & $C_{w}^{a}=0.90$ & $C_{w}^{b}=0.79$ \\
Longitudinal CoG (rel. midship) & $X_{G}^{a}=0.086 \mathrm{~m}$ & $X_{G}^{b}=-0.01 \mathrm{~m}$ \\
Vertical CoG (rel. calm waterline) & $Z_{G}^{a}=-0.052 \mathrm{~m}$ & $Z_{G}^{b}=0.012 \mathrm{~m}$ \\
Radius of inertia for roll & $r_{44}^{a}=0.175 \mathrm{~m}$ & $r_{44}^{b}=0.103 \mathrm{~m}$ \\
Radius of inertia for pitch & $r_{55}^{a}=1.008 \mathrm{~m}$ & $r_{55}^{b}=0.604 \mathrm{~m}$ \\
Radius of inertia for yaw & $r_{66}^{a}=1.008 \mathrm{~m}$ & $r_{66}^{b}=0.604 \mathrm{~m}$ \\
\hline
\end{tabular}

Table 4

Corrections for model set-up of Ship_b, non-dimensionalized using $\rho, V_{b}, L_{b}, g$ and $A_{w b}$ (Ronæss, 2002)(Ronæss, 2002)(Ronæss, 2002)

\begin{tabular}{lccc}
\hline Component, $i j$ & 33 & 55 & 35,53 \\
\hline Additional inertia, $I_{i j}$ & $1.6 \mathrm{E}-01$ & $5.5 \mathrm{E}-02$ & $-7.2 \mathrm{E}-04$ \\
Additional damping, $B_{i j}$ & $5.2 \mathrm{E}-03$ & $1.6 \mathrm{E}-03$ & $-2.6 \mathrm{E}-03$ \\
Additional restoring, $C_{i j}$ & $4.8 \mathrm{E}-04$ & $1.5 \mathrm{E}-04$ & $-2.1 \mathrm{E}-06$ \\
\hline
\end{tabular}



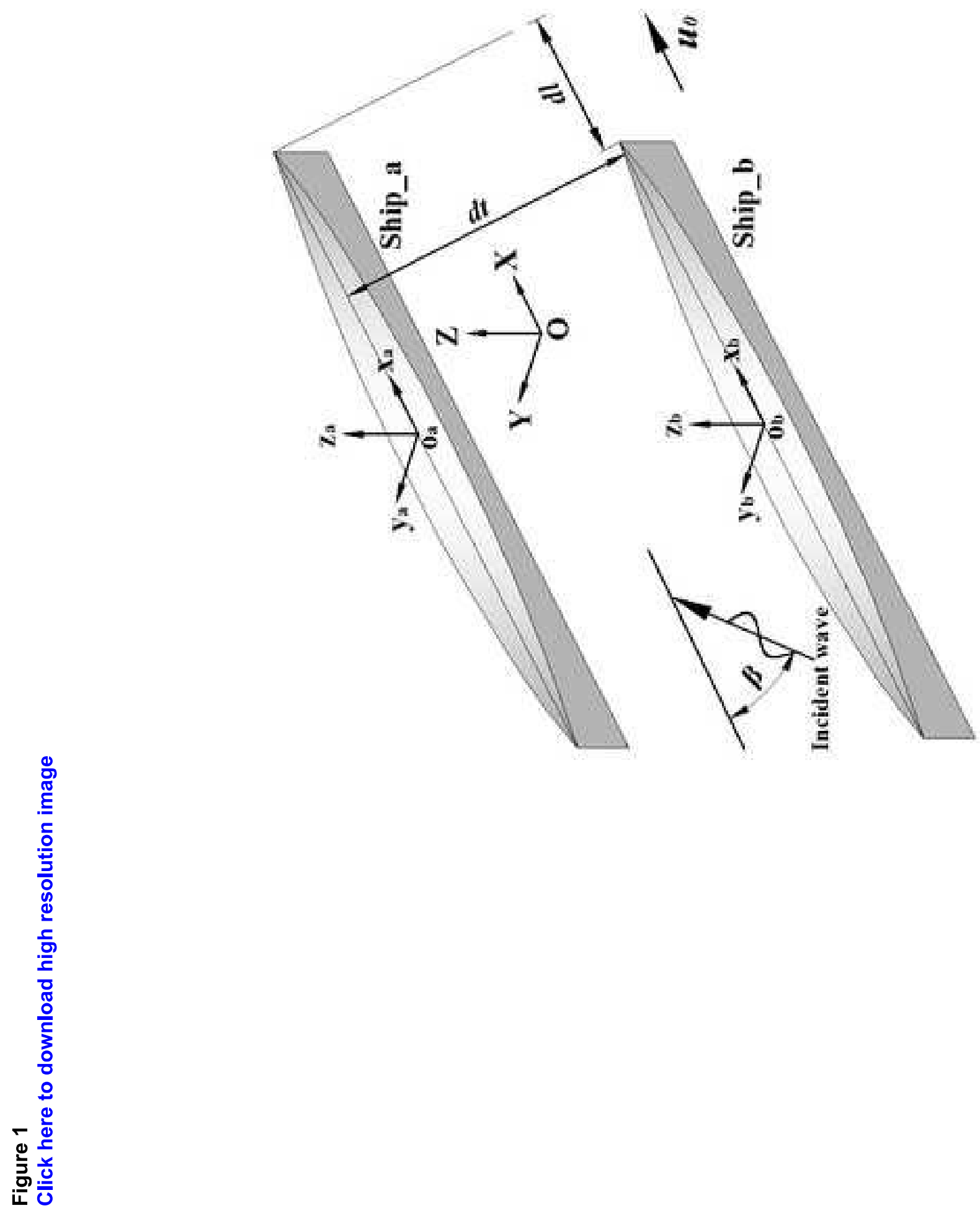



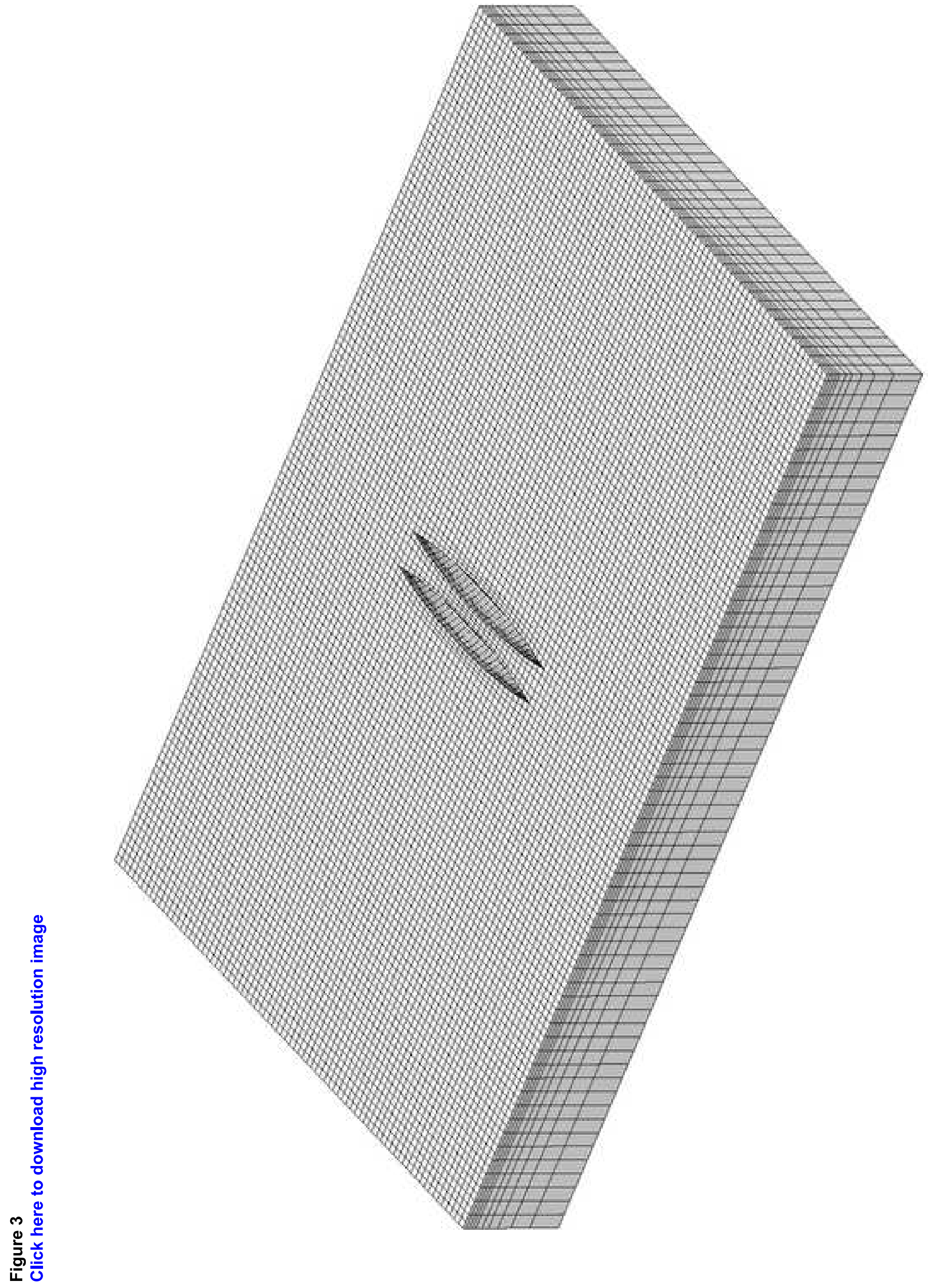



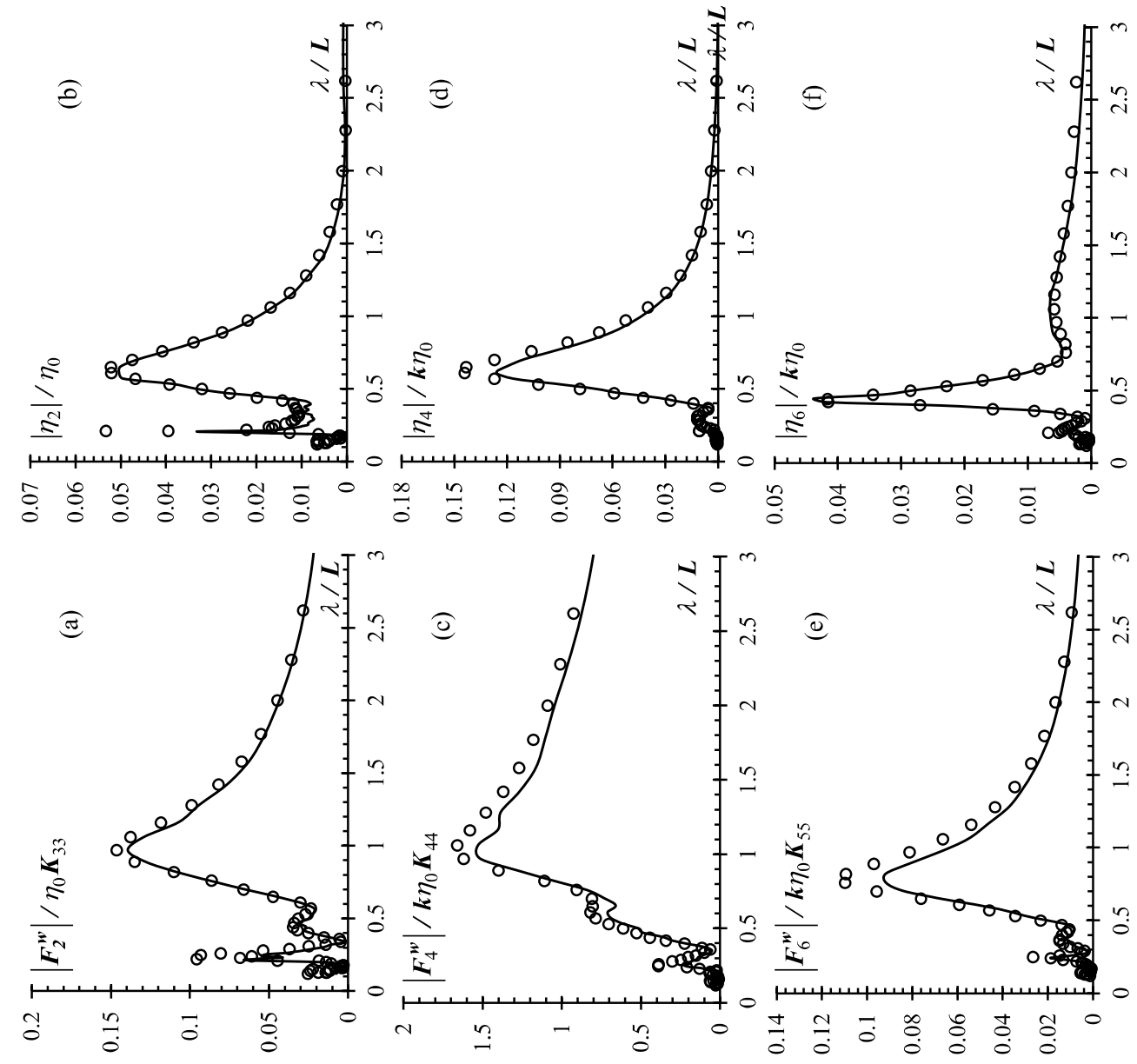


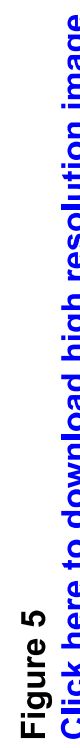

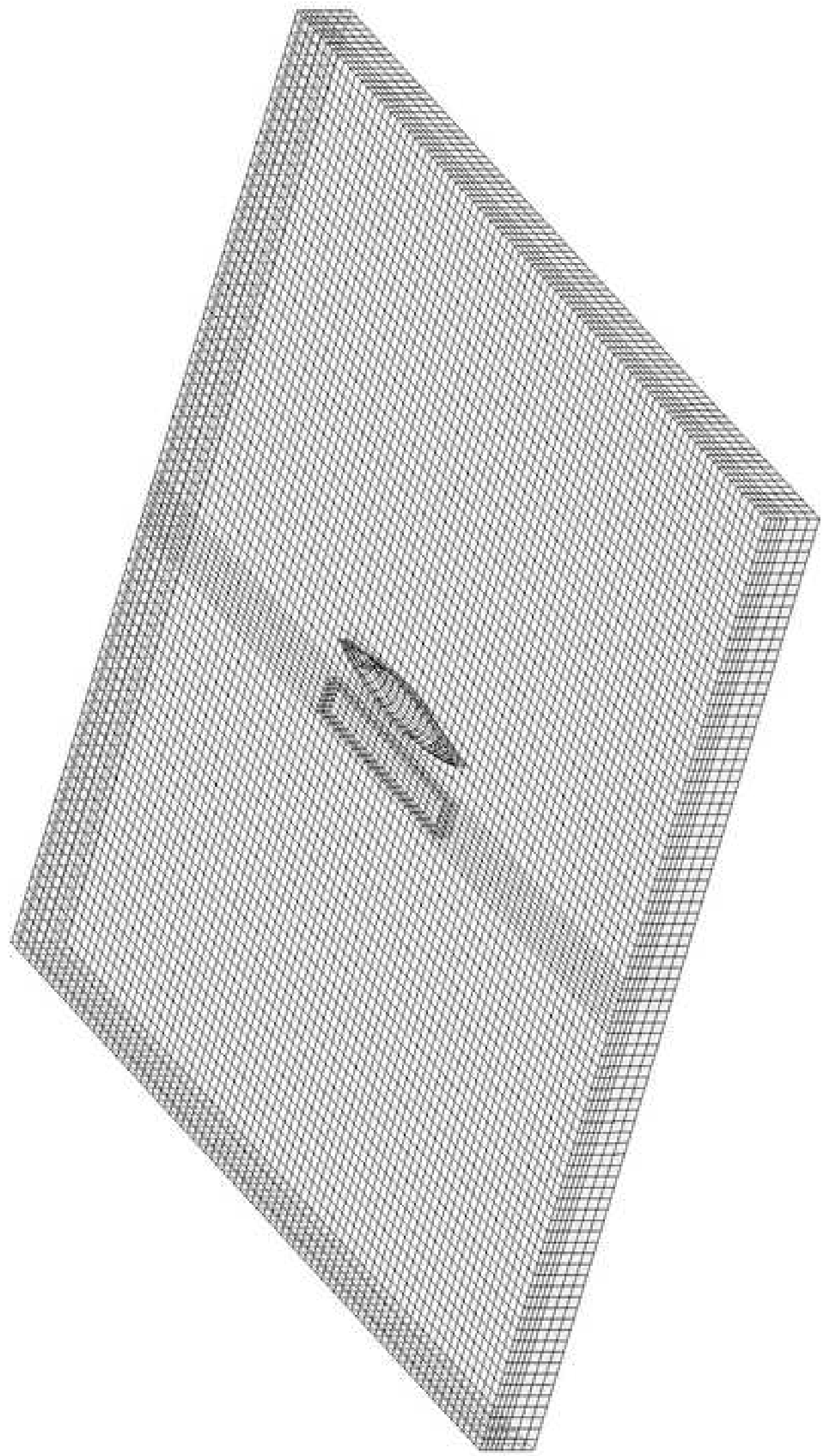



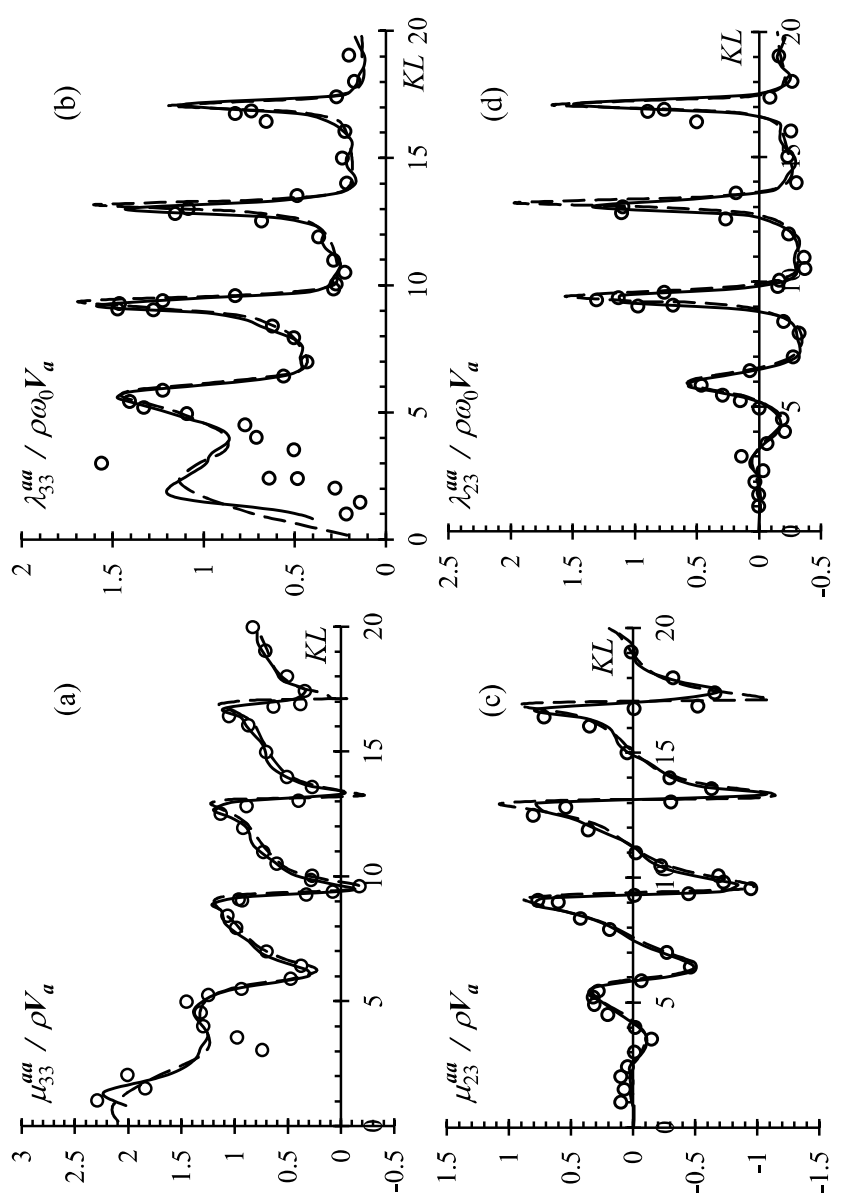


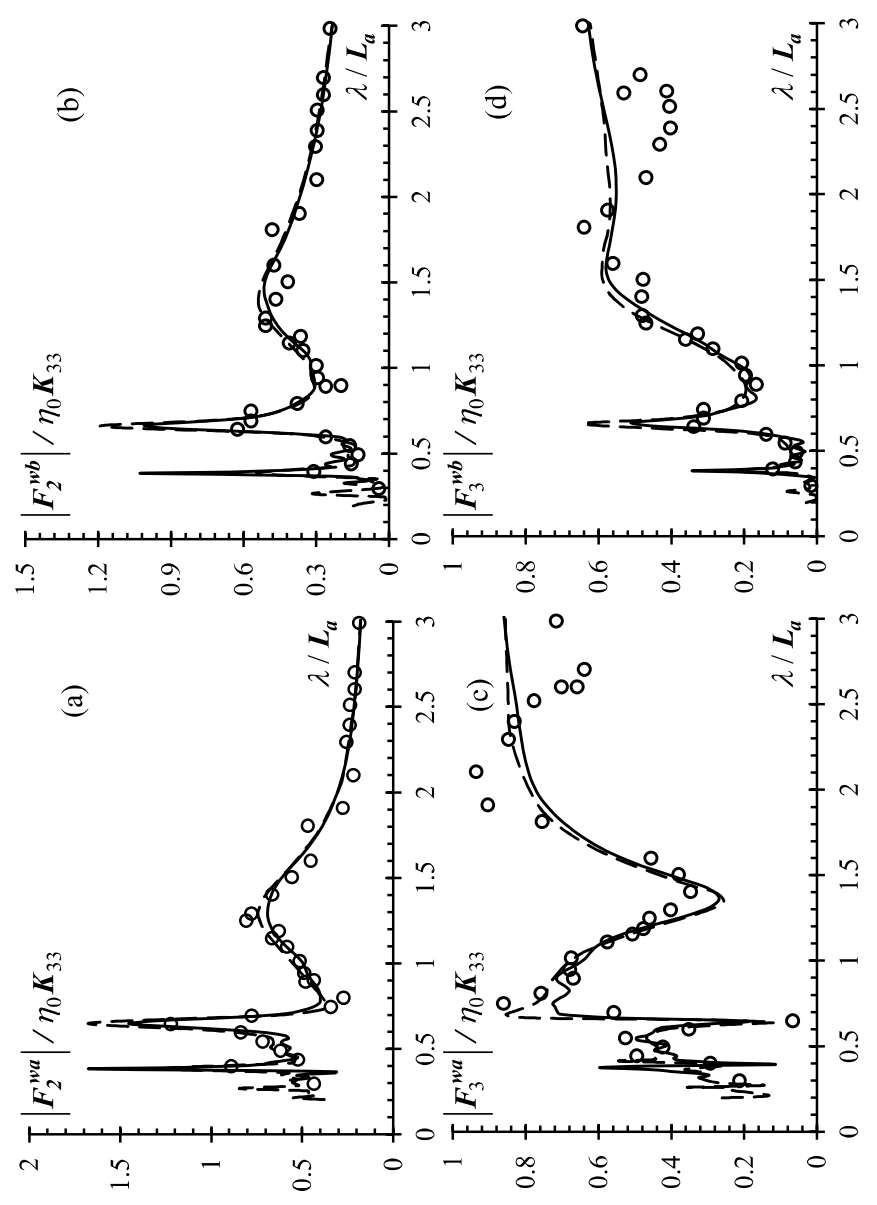



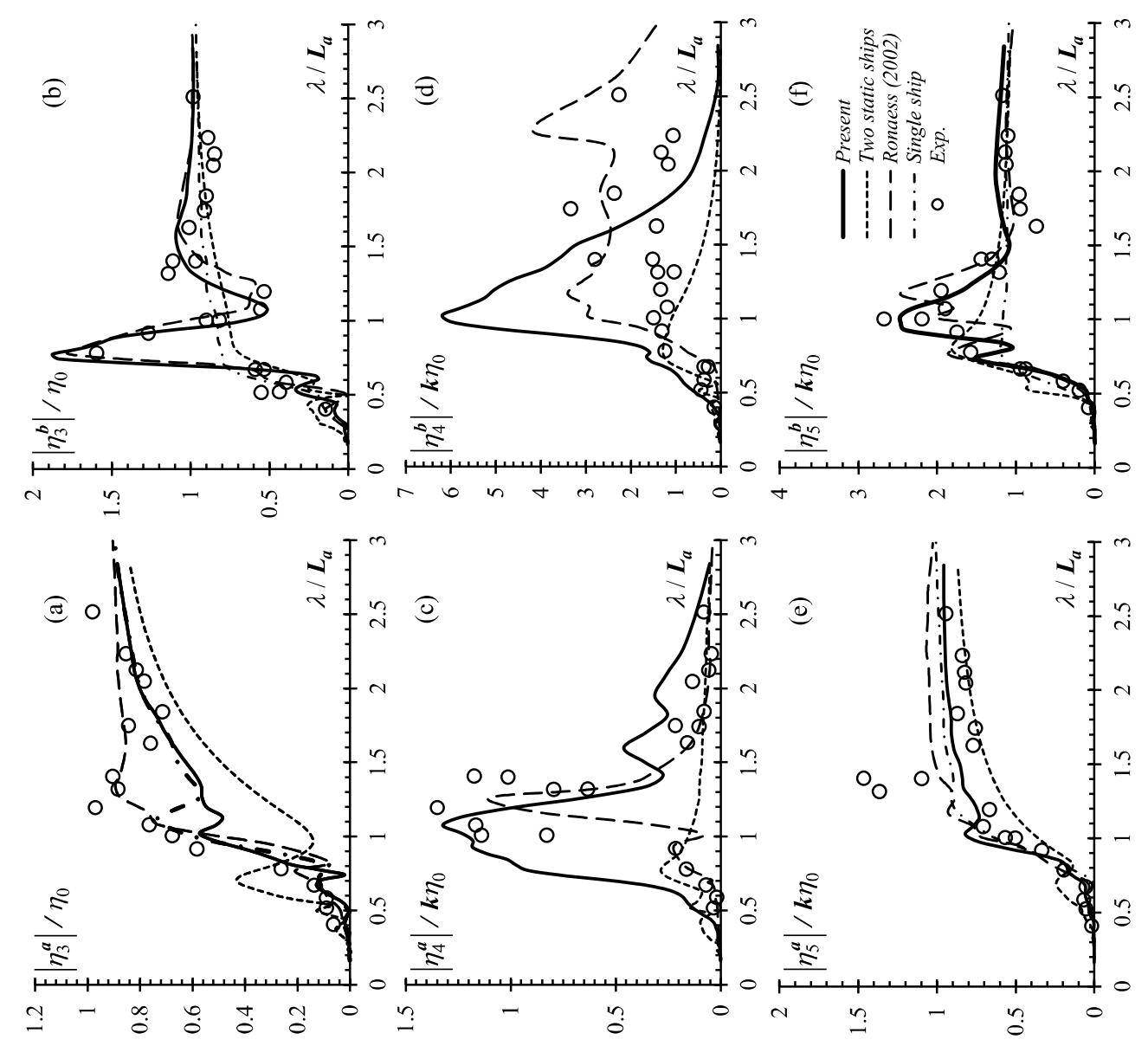

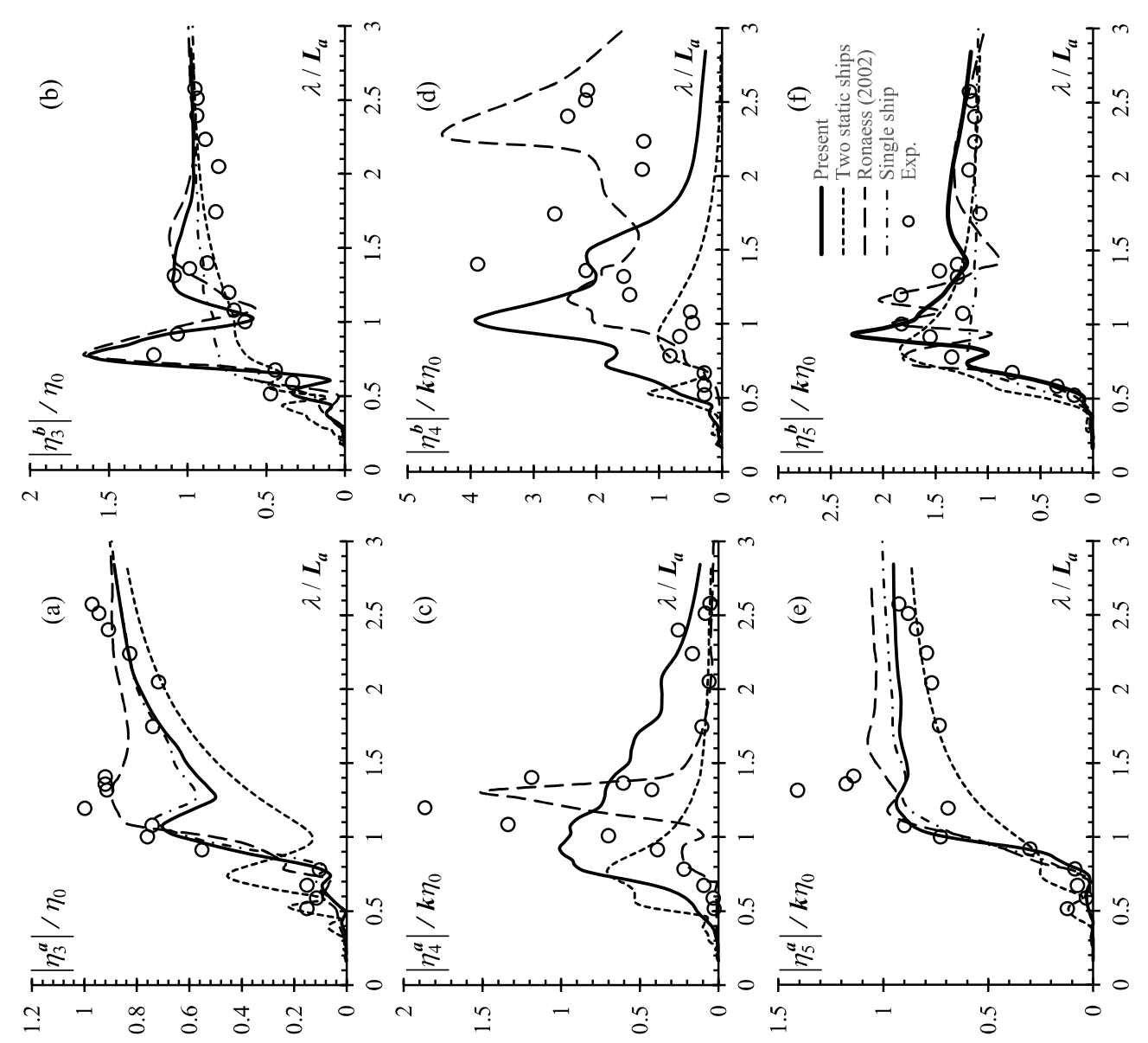

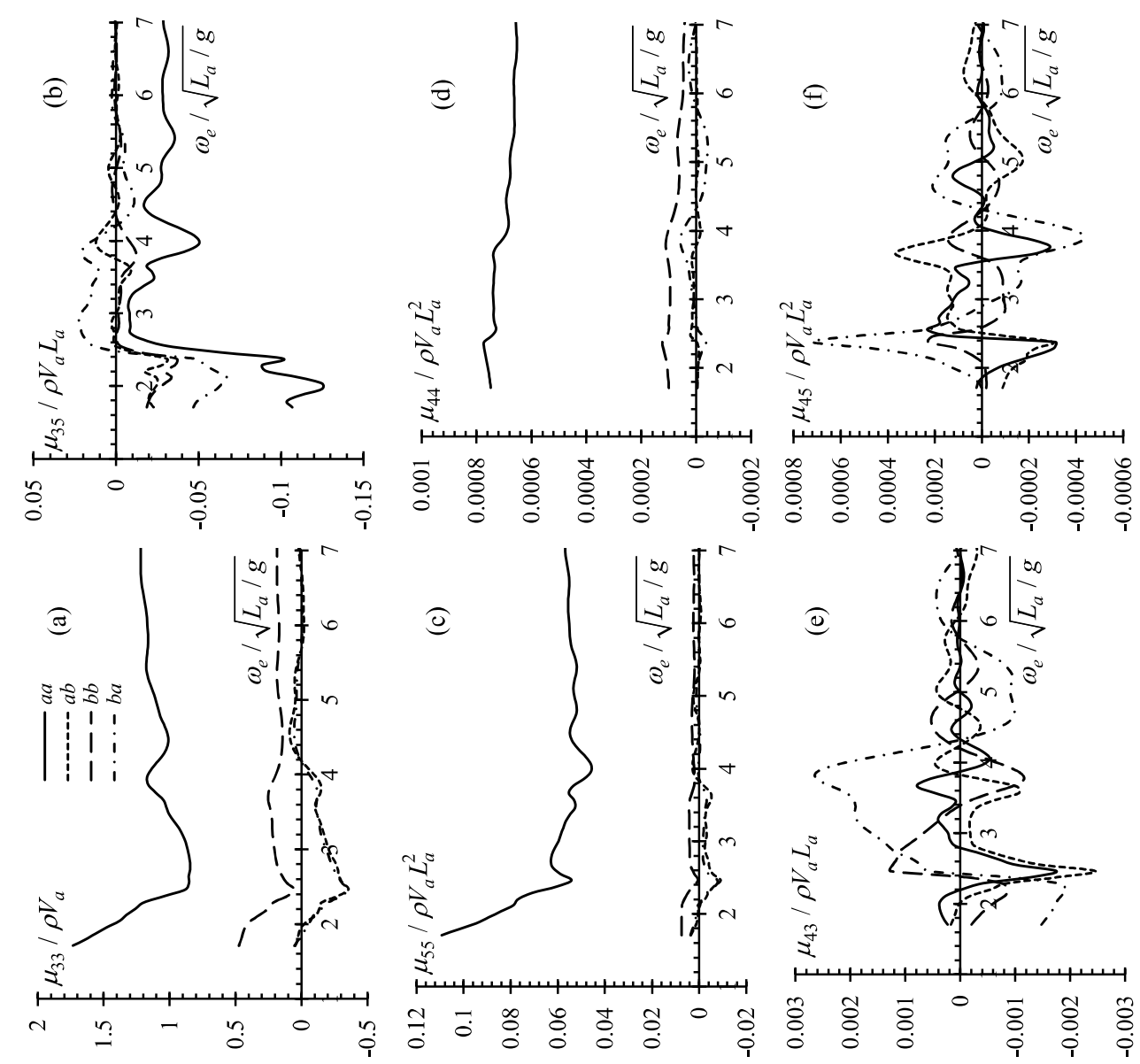


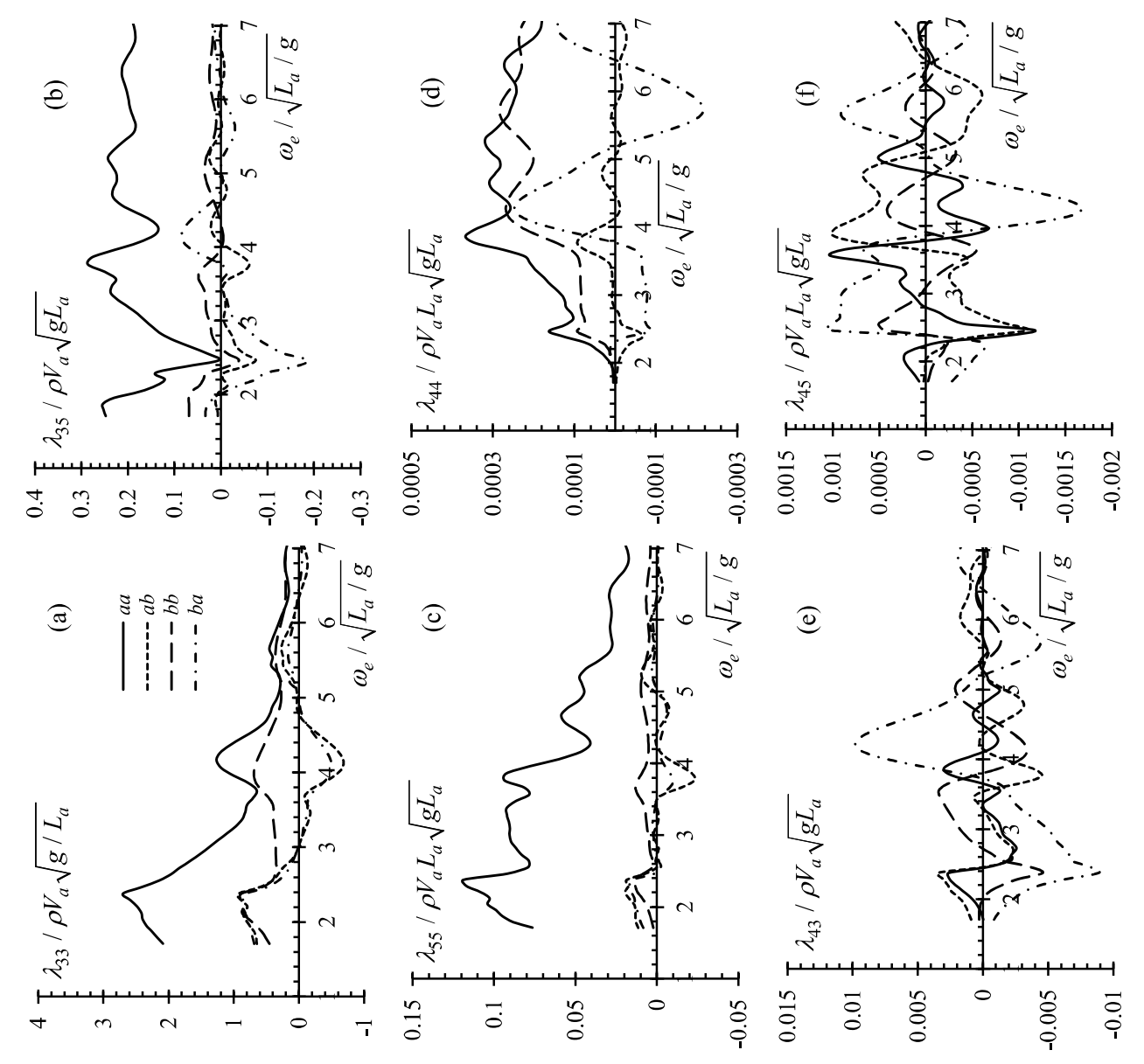



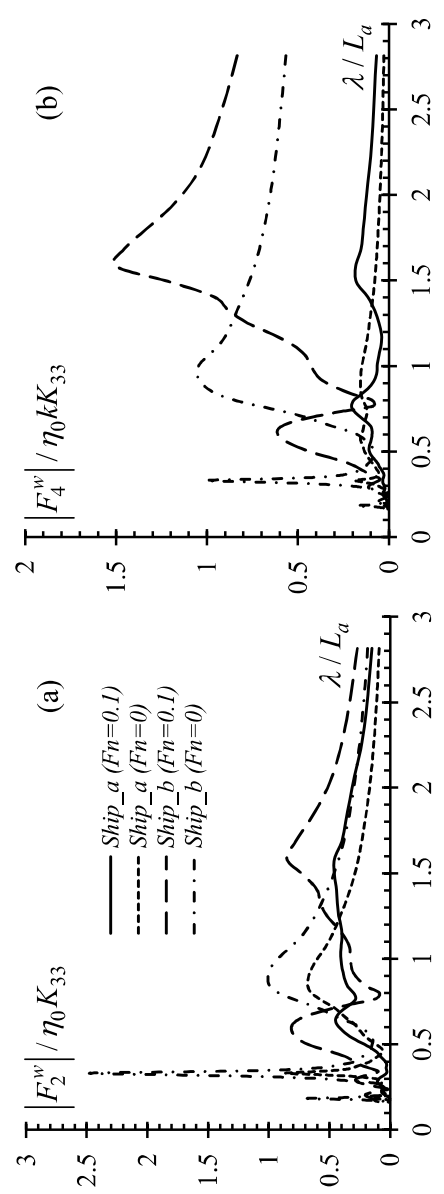

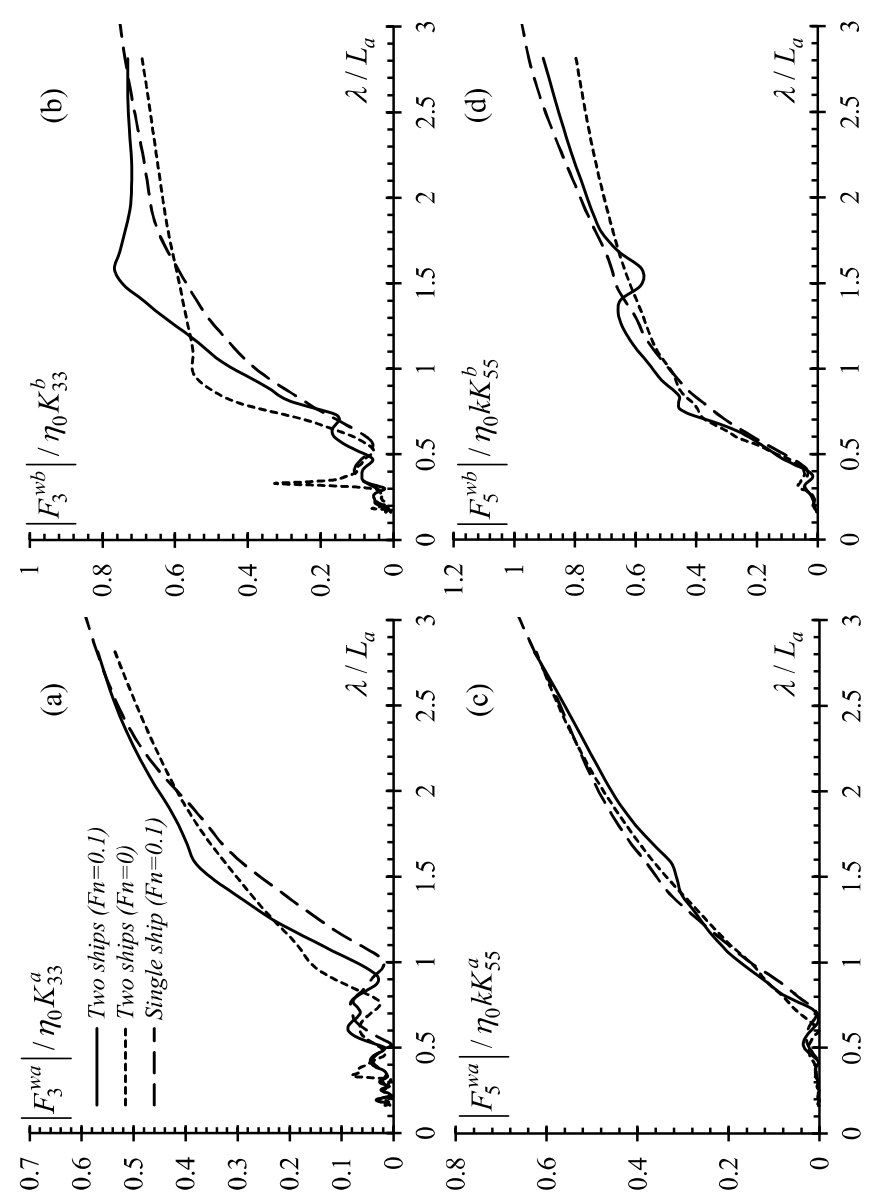

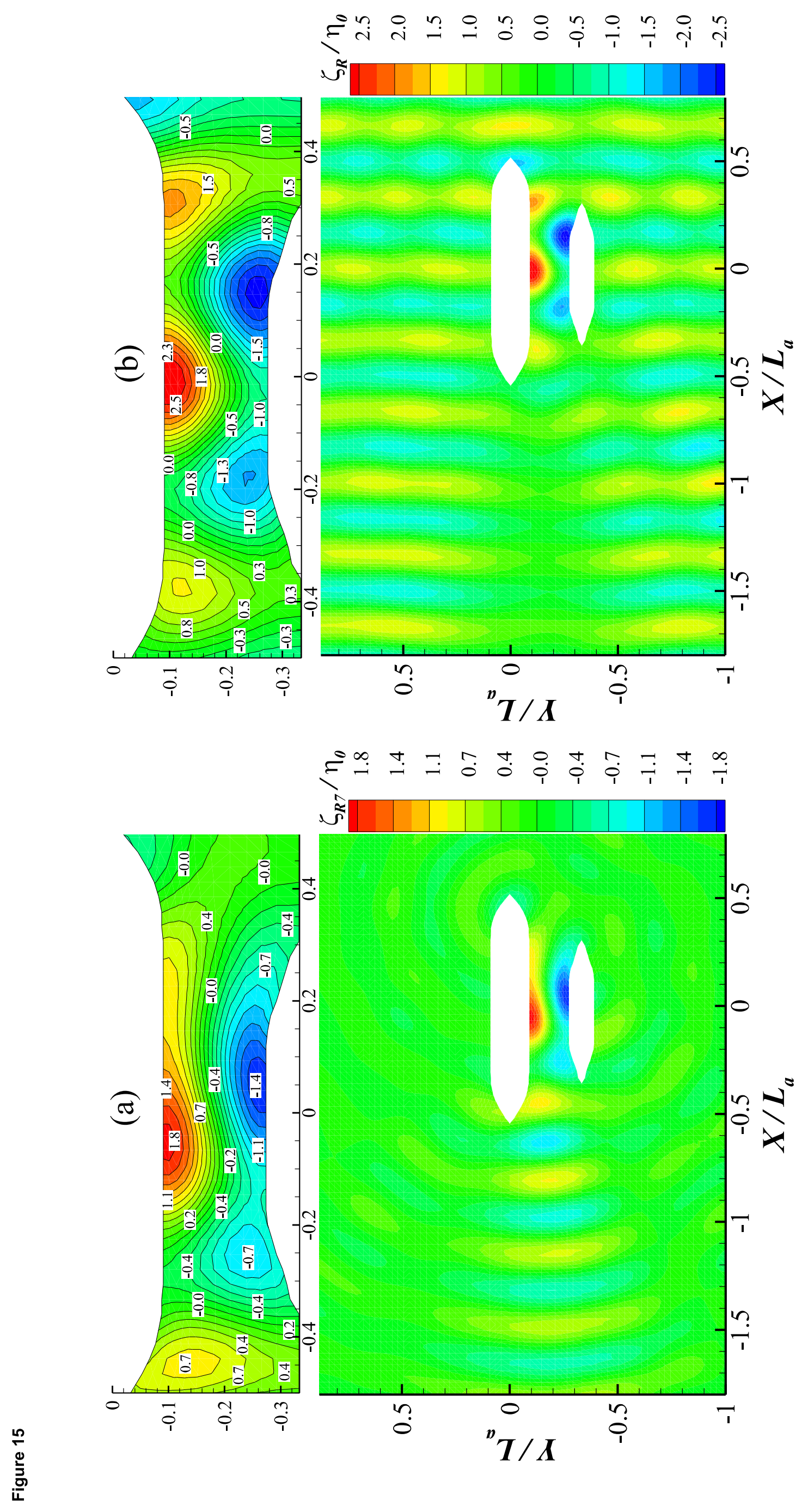


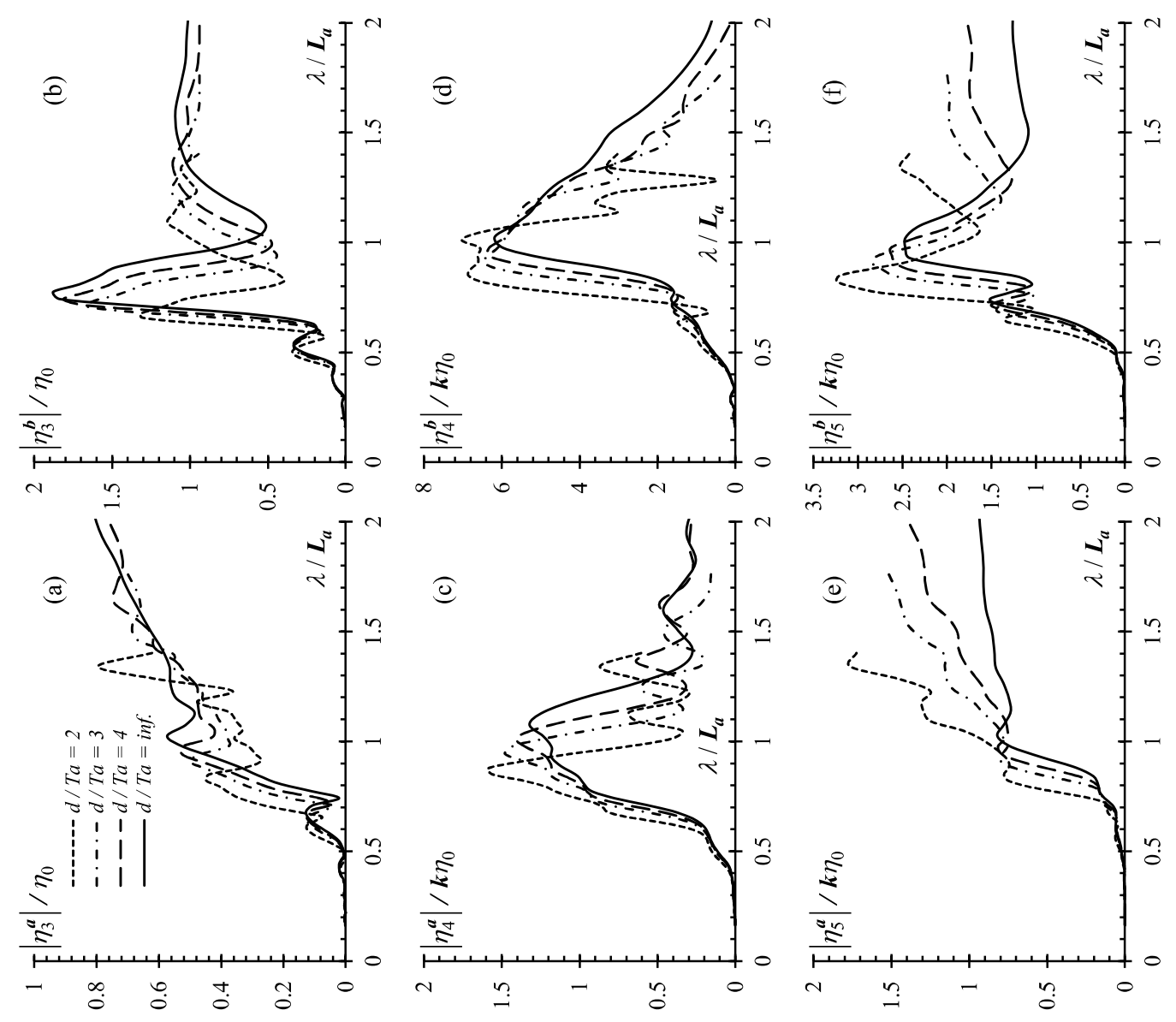




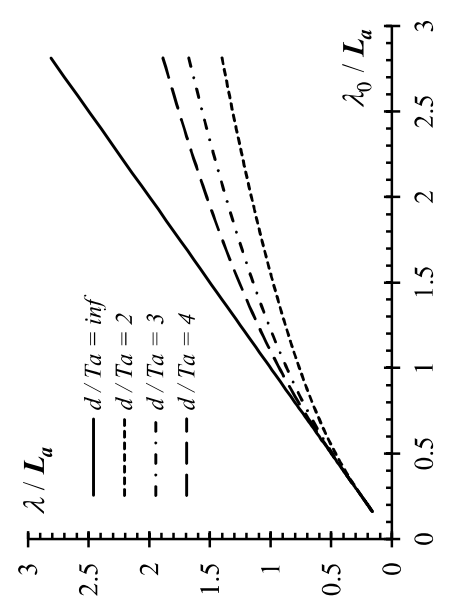




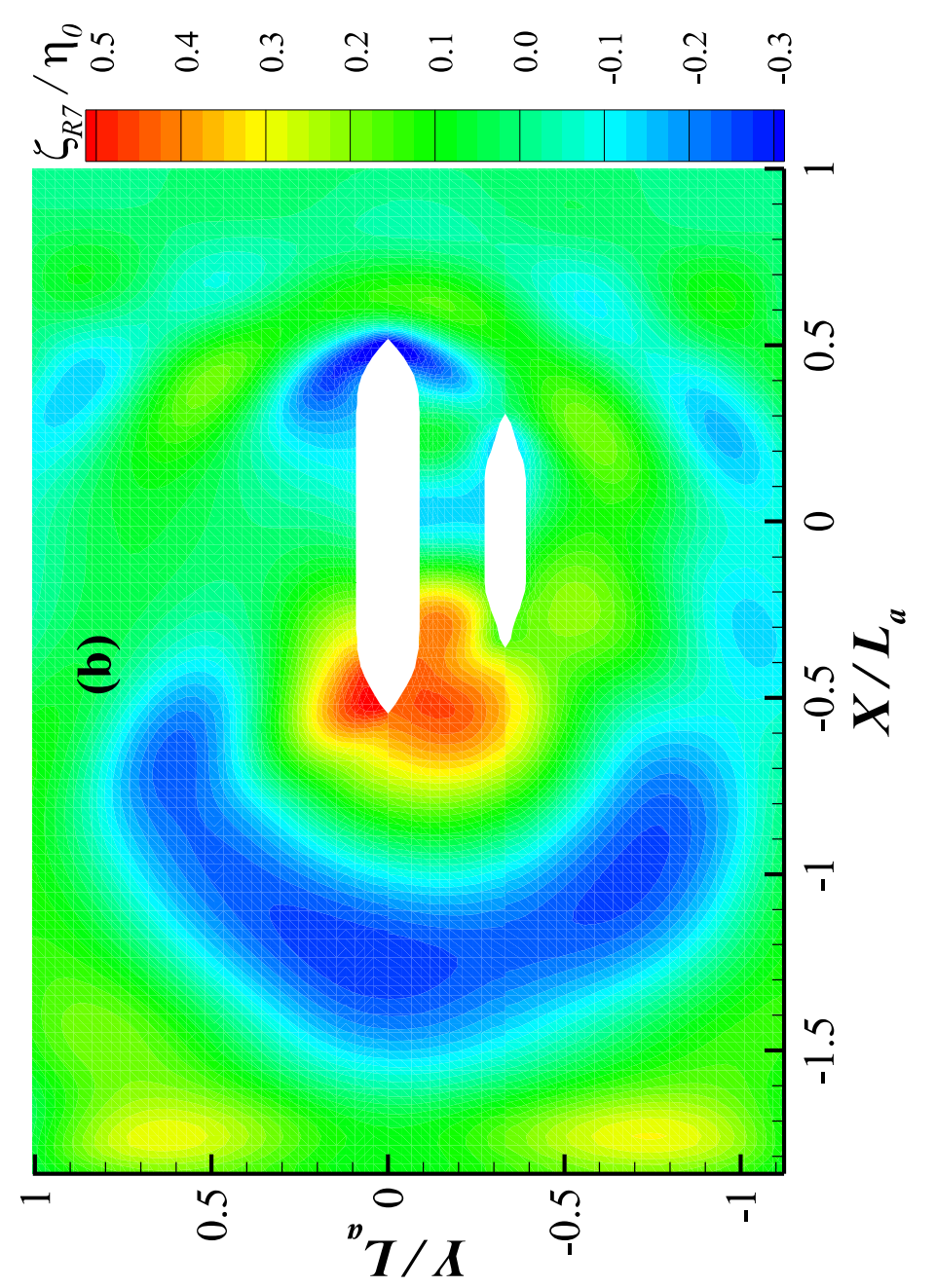

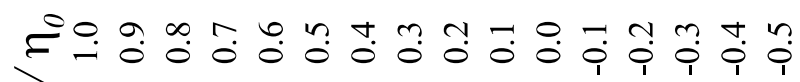

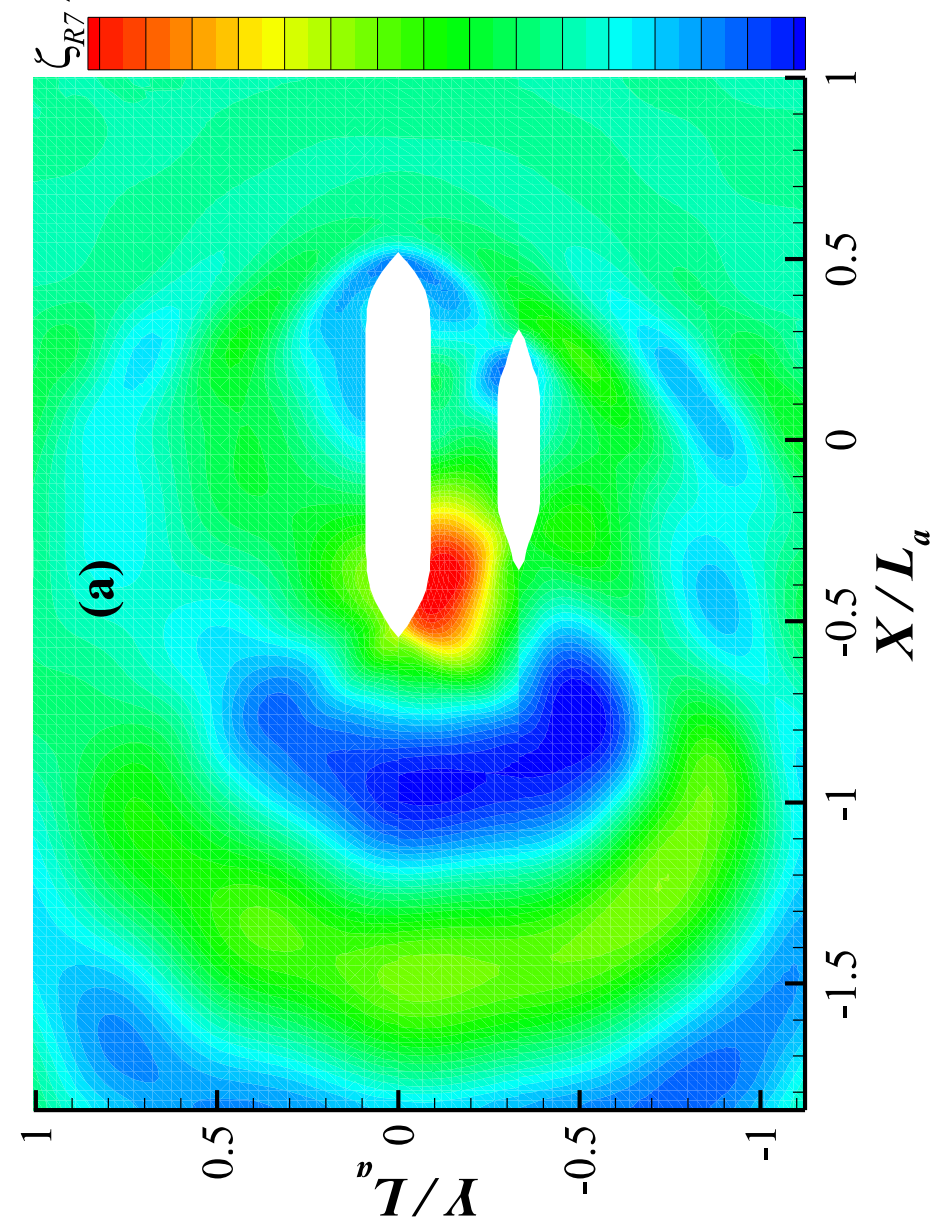

